\title{
Modulating the Efficacy of Carbonic Anhydrase Inhibitors through \\ Fluorine Substitution
}

Emanuela Berrino, ${ }^{\mathrm{a}}$ Bastien Michelet, ${ }^{\mathrm{b}}$ Agnès Martin-Mingot, ${ }^{\mathrm{b}}$ Fabrizio Carta, ${ }^{\mathrm{a}}$ Claudiu T. Supuran ${ }^{\mathrm{a}}$ and Sébastien Thibaudeau ${ }^{\mathrm{b}}$

${ }^{a}$ University of Florence, NEUROFARBA Dept., Sezione di Scienze Farmaceutiche e Nutraceutiche, Via Ugo Schiff 6, 50019 Sesto Fiorentino (Florence), Italy.

b Superacid Group in “Organic Synthesis” Team, Université de Poitiers, CNRS UMR 7285 IC2MP, Bâ t. B28, 4 rue Michel Brunet, TSA 51106, 86073 Poitiers Cedex 09, France

\section{Introduction}

Enhancement of therapeutic efficacy and improvement of pharmacological properties of a drug can be tuned through fluorine atom(s) insertion. ${ }^{[1]}$ This strategy is now well-established, ${ }^{[2]}$ as revealed by the increasing number of fluorine-containing compounds currently in phase II-III clinical trials. ${ }^{[3]}$ The insertion of fluorine atom(s) into a scaffold can affect its physico-chemical properties, ${ }^{[4]}$ with evident consequences on the drug biological features. ${ }^{[5]}$ Overall these benefits make the fluorine as "the second-favorite heteroatom" after nitrogen in drug design. ${ }^{[6]}$ Fluorine is commonly used to tune amine groups basicity which in turn affects biomembrane penetration and bioavailability of drugs or even to protect them from metabolic transformations. ${ }^{[7,8]}$ State of-the-art application also accounts for the use of fluorine to induce preferential molecular conformations as a relevant strategy for molecular design in medicinal chemistry. ${ }^{[8-16]}$ Here we set the research topic by scrutinizing the most relevant studies referred to fluorinated inhibitors of the metalloenzymes Carbonic Anhydrases (CAs; EC 4.2.1.1) and deciphering the effect that fluorine insertion could induce. Recent reports on ${ }^{19} \mathrm{~F}$ NMR based approaches to decipher ligand-enzyme interactions within CAs are also discussed.

CAs are virtually expressed in every living organism being encoded by 8 genetically unrelated families (i.e. $\alpha-, \beta-, \gamma-, \delta-, \zeta-, \eta-, \theta-$ and $\left.\mathrm{t}^{-}\right)$. The $\alpha$-class is expressed in humans, up to 15 isoforms with diverse cellular and tissue distribution have been identified so far. These enzymes are highly efficient in catalyzing the equilibrium in Eq. 1, essential in sustaining the cellular metabolic pathways, ${ }^{[17-20]}$ through a well-defined catalytic mechanism which actively involves a Zn (II) ion. ${ }^{[17,18,21]}$

$$
\mathrm{CO}_{2}+\mathrm{H}_{2} \mathrm{O} \rightleftharpoons \mathrm{H}_{2} \mathrm{CO}_{3} \rightleftharpoons \mathrm{HCO}_{3}^{-}+\mathrm{H}^{+} \text {(Eq. 1) }
$$

As peculiar structural feature, CAs have their active site split into a hydrophilic and a hydrophobic halves facing each other (Figure 1). Such an architecture contributes itself to the enzymatic efficiency by creating preferential ways for the substrate $\left(\mathrm{CO}_{2}\right)$ to feed in and for the products $\left(\mathrm{H}^{+}, \mathrm{HCO}_{3}{ }^{-}\right)$to be expelled out of the enzyme. ${ }^{[21-23]}$ Large series of compounds have been explored and/or developed as CA inhibitors (CAIs), ${ }^{[21,24]}$ and many were proved to exert their activity through 4 distinct mechanisms (Figure 1). ${ }^{[21,25-33]}$ 


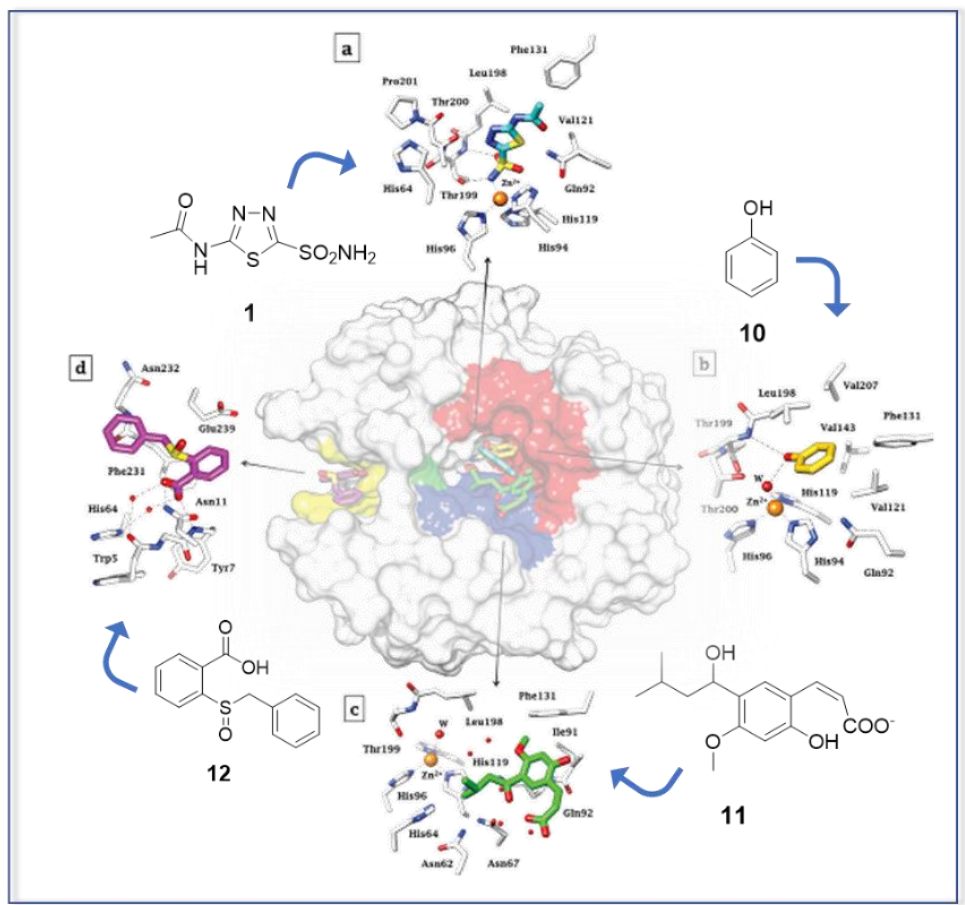

a) Metal binding moieties

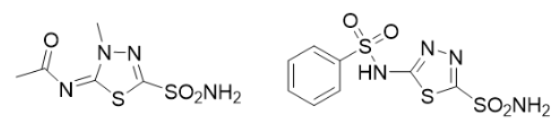

2

3

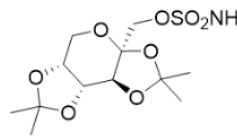

4

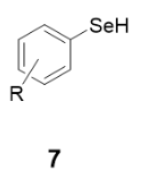

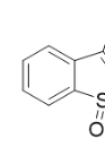

5

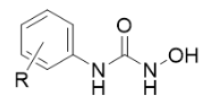

8

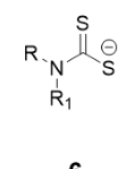

6

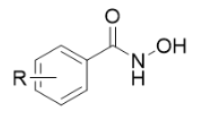

9

Figure 1. Solvent accessible surfaces of CA II: residues delimiting the hydrophobic half are in red, the hydrophilic ones are in blue. Main inhibition mechanisms of the CAIs (PDBs 3HS4, 3F8E, 4QY3). a) Acetazolamide (AAZ) 1, and other metal binding moieties 2-9; b) compounds anchoring the zinc-bound water molecule, i.e. phenol 10, c) compounds occluding the entrance of the active site, i.e. 2-hydroxy-cinammic acid $11 \mathrm{~d}$ ) out of the binding site inhibitors, i.e. benzoic acid 12. The hydrophobic adjacent pocket where inhibitors bind outside the active site is shown in yellow. ${ }^{[21,34]}$

Using CA II isoform as model enzyme target, this review will focus on metal binding compounds bearing the sulfonamide group, which constitute the wider and the most studied class of inhibitors to date. ${ }^{[31,35]}$ Such a moiety coordinates in the deprotonated form, acting as fourth ligand to the enzymatic metal ion upon displacement of the water/ $\mathrm{OH}^{-}$molecule according to slightly distorted tetrahedral geometry. ${ }^{[21]}$ Metal chelation with auxiliary hydrogen bonds represent a highly conserved binding cluster which confers to such a moiety unique $\mathrm{CA}$ inhibitory potencies but also indiscriminate activities against the human expressed isoforms (Figure 2). ${ }^{[21]}$ Most of the side effects of the sulfonamide-based CA inhibitors are due to the inhibition of the cytosolic isoform CA II, abundant in many tissues/organs, and involved in numerous physiological functions (i.e. $\mathrm{pH}$ homeostasis, secretion of electrolytes, transport of anions). ${ }^{[1,24,36]}$ Without claiming completeness, this study would provide key statements on why and how fluorine atom(s) should be incorporated in this type of CA inhibitors affecting their potency or selectivity towards specific isoforms, with key examples of fluorinated inhibitors targeting the tumor associated isoform CA IX and the central nervous system (CNS) abundantly expressed CA VII selected at this aim. ${ }^{[37,38]}$ 


\author{
Effects on \\ sulfonamide $\mathrm{pKa}$ and \\ protein interactions
}

\section{Potency}

T

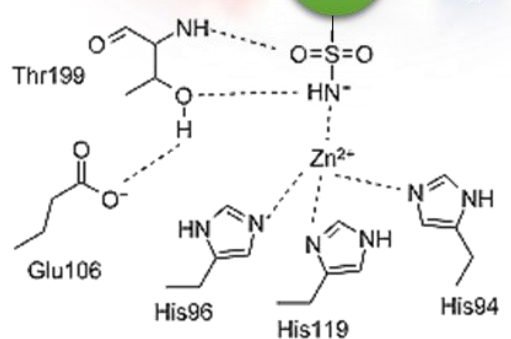

\section{Selectivity}

Effects on

hydrophilic/hydrophobic

interactions

Figure 2. Key interactions between a generic sulfonamide within the CA II active site. ${ }^{[21]}$ Manipulations on $\mathbf{R}$ section preferentially affect the ligand potency whereas on the tail (T) major relevance for isoform selectivity are observed. ${ }^{[21,39,40]}$

\section{Fluorinated sulfonamides as CAI}

Clear impact of the fluorine on CA II inhibition potency of sulfonamide was first offered by the $\mathrm{CF}_{3}$ $\mathrm{SO}_{2} \mathrm{NH}_{2} 13$ when compared to its non-halogenated counterpart 14. In vitro significative $\mathrm{IC}_{50}$ lowering values ( 5 orders of magnitude) were attributed to the sulfonamide $\mathrm{pK}_{\mathrm{a}}$ reduction as a consequence of the $\mathrm{CF}_{3}$ electronwithdrawing effect (Figure 3a). ${ }^{[41]}$

a)

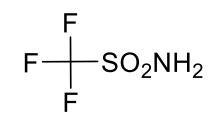

13

hCA II
$\mathrm{K}_{l}=2 \times 10^{-9} \mathrm{M}$

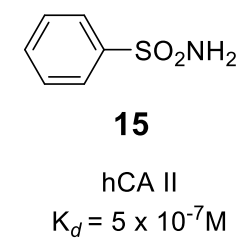

b)

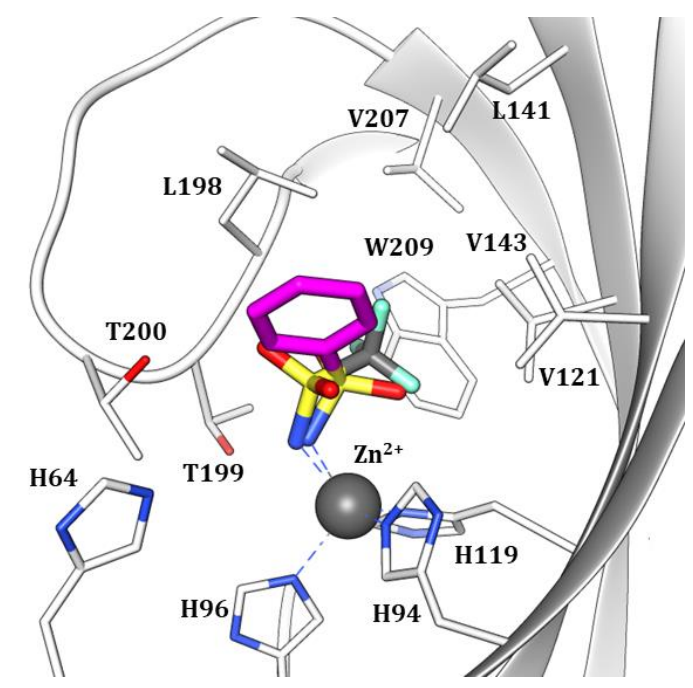

Figure 3. a) Structures of trifluoromethanesulfonamide 13, methanesulfonamide $\mathbf{1 4}$ and benzenesulfonamide 15; b) Structural superposition of CA II/13 (yellow, PDB 1BCD) and CA II/15 (red, PDB 2WEJ). ${ }^{[42]}$ 
$\mathrm{CF}_{3}-\mathrm{SO}_{2} \mathrm{NH}_{2} \mathrm{I3}$ revealed itself also an adequate model to investigate the influence of the fluorine on the orientation of the ligand within the enzymatic cavity. Structure superposition of 13-CA II and 15-CA II adducts showed the hydrophobic $\mathrm{CF}_{3}$ moiety oriented inwards the active site and engaged in van der Waals interactions with the hydrophobic section of the cleft, thus opposite to the usually observed orientation of the R moiety as for classical aromatic/heteroaromatic sulfonamides (Figure 3b) ${ }^{[42]}$ As a consequence the sulfonamide in 13CA II was rotated $180^{\circ}$ around the sulfur-nitrogen bond with respect to 15-CA II.

Replacement of the $\mathrm{CH}_{2}$ in $\mathbf{1 6}$ with a $\mathrm{CF}_{2}$ instead (i.e. as in 17) determined a CA II $\mathrm{K}_{I}$ lowering up to 8fold. ${ }^{[43]}$ Again, the inhibition data were supported by different orientation of the ligands within the CA II cavity (Figure 4). ${ }^{[44]}$
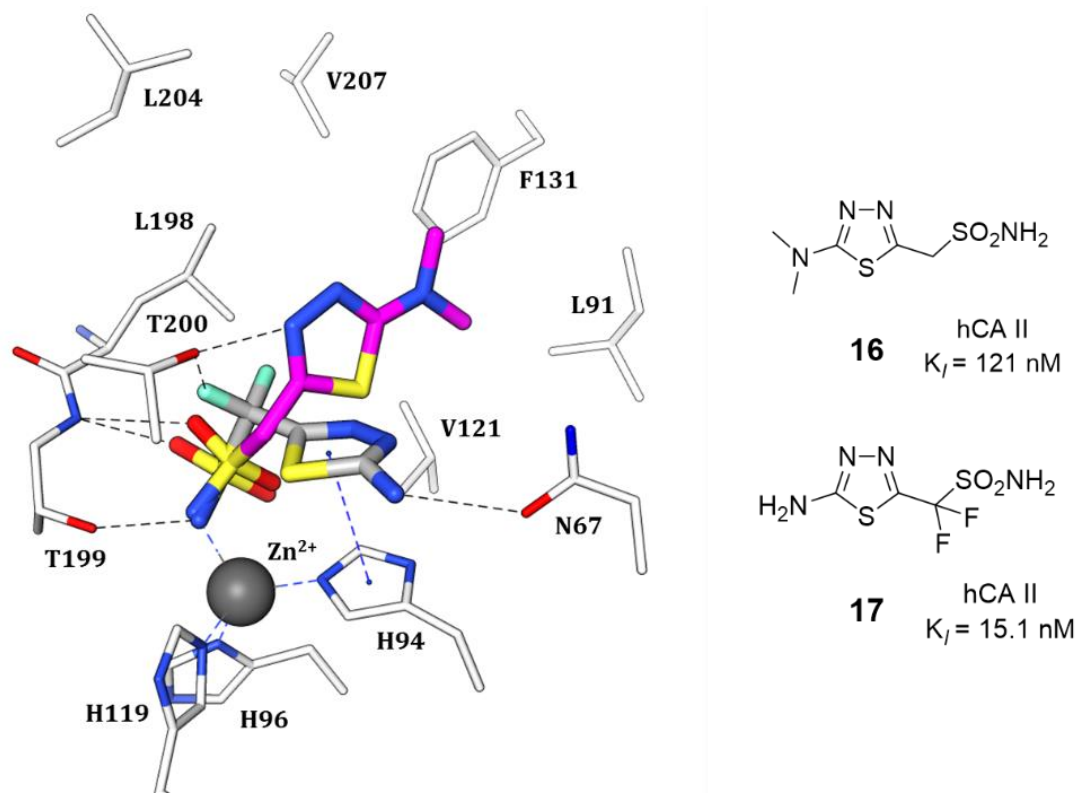

Figure 4. CA II in complex with 16 (magenta, PDB 3BL0) and (B) 17 (gray, PDB 2EU3). ${ }^{[4]}$

The thiadiazole moiety in $\mathbf{1 7}$ was found pointing towards the hydrophilic cavity section and hold by a $\pi$-stacking interaction with His94 and a H-bond of the amine with Asn62 by means of a water bridge (not shown) and Asn67. Further stabilization is given by the interaction occurring between the $\mathrm{CF}_{2}$ with Thr200. The role of fluorine in the binding of $\mathbf{1 7}$ is therefore attributable to the withdrawing effect on the sulfonamide moiety, as in agreement with the example before stated, and to the direct interaction of the $\mathrm{CF}_{2}$ moiety with an aminoacidic residue (Figure 4). Detailed analysis of $\mathbf{1 6}$ and $\mathbf{1 7}$ poses reveals that the primary amine in the latter makes use of hydrogen bonds to lock the ligand into a favorable orientation for the fluorine interaction to occur. (Figure 4). ${ }^{[44]}$

The discussed examples afford direct evidences on the role of fluorine(s) on ligand-CA interactions, but also prove the difficulty to dissect the effective overall contribution as: $i$ ) the sulfonamide itself accounts up to the $65 \%$ of the free energy binding, and thus it scales down the other interactions (i.e. hydrogen bonds and hydrophobic contacts) to mere "accessories" difficult to predict and/or to calculate $\left.{ }^{[45]} i i\right)$ the controversial 
nature of fluorine and features of the C-F bond need to be properly considered as well as the position of fluorine within the ligand molecule. Below, we present a selection of examples indicative of the effects on ligand binding due to the introduction of fluorine(s) within CAIs of the arylsulfonamide type together with related advantages for biomedical purposes (Figure 5)..$^{[4,46]}$

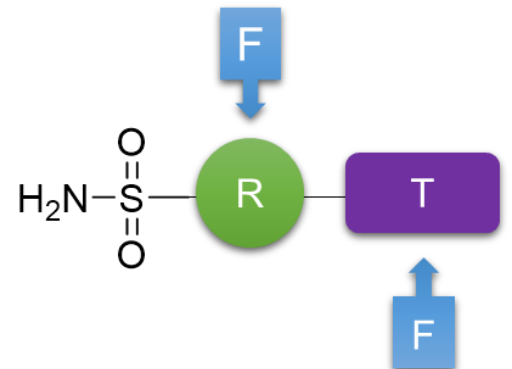

Figure 5. Fluorine insertions on CAIs; $\mathrm{R}=$ ring and $\mathrm{T}=$ tail.

\subsection{Fluorine on the "ring"}

Considering the simplest benzene sulfonamide inhibitor 15 that could be tested and compared, the impact of the fluorine substitution and its comparison with related halogenated congeners can be considered as a preliminary important study. Single fluorine insertion as in CAI 20 induced far superior free binding energy $\left(\Delta \mathrm{G}^{\circ}\right)$ and affinity $\left(\mathrm{K}_{\mathrm{d}}\right)$ values for CA II when compared to the unsubstituted $\mathbf{1 5}$, its related fluoro isomer 19 or chloro analogue 18 (Figure 6). ${ }^{[47]}$ Particularly relevant are the diverse $\Delta \mathrm{H}^{\circ}$ and $\Delta \mathrm{S}^{\circ}$ contribution values observed for the ortho-19 and meta-20 fluoro substituted compounds, being the affinity increase for the former mainly related to a significant enthalpic gain, whereas for the latter a large entropic contribution was observed. Evaluation of X-ray crystal structures of 15, 18-20 in adduct with CA II allowed to decipher these thermodynamic features (Figure 6). ${ }^{[47]}$ The interaction of the fluorine in $\mathbf{1 9}$ with Thr200 was found responsible for the observed enthalpic gain. Such a contribution was missing in the chloro analogue 18, as the larger halogen forced the molecule to assume different orientation within the enzyme active site (Figure 6). As for the meta-F derivative 20 , favorable dispersive interactions between the halogen and the hydrophobic wall of the CA justify the entropic gain and the favorable $K_{d}$ values observed. ${ }^{[47]}$ These findings were further sustained by kinITC and high-resolution X-ray crystallographic data (Figure 6). ${ }^{[48]}$ 


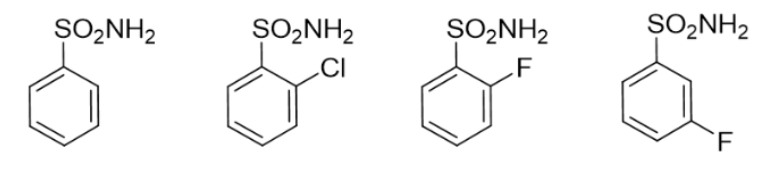

\begin{tabular}{r|c|c|c|c|}
\multicolumn{1}{c}{} & \multicolumn{1}{c}{$\mathbf{1 5}$} & $\mathbf{1 8}$ & \multicolumn{1}{c}{19} & $\mathbf{2 0}$ \\
\cline { 2 - 5 }$\Delta \mathbf{G}^{[\mathrm{a}]}$ & -8.3 & -8.1 & -8.9 & -9.4 \\
\cline { 2 - 5 }$\Delta \mathbf{H}^{[\mathrm{a}]}$ & -7.5 & -6.7 & -9.4 & -7.5 \\
\cline { 2 - 5 }$-\mathbf{T} \Delta \mathbf{S}^{[\mathrm{a}]}$ & 0.8 & 1.4 & -0.05 & 1.9 \\
\cline { 2 - 5 } $\mathbf{K}_{\mathrm{d}}(\mathbf{n M})$ & 839 & 1125 & 314 & 118 \\
\cline { 2 - 5 } $\mathbf{K}_{\text {on }} / \mathbf{M}^{-1} \mathbf{s}^{-1}$ & $2.00 \mathrm{E}+04$ & - & $7.36 \mathrm{E}+04$ & $1.11 \mathrm{E}+05$ \\
\cline { 2 - 5 } $\mathbf{K}_{\text {off }} / \mathbf{S}^{-1}$ & $1.00 \mathrm{E}-02$ & - & $1.47 \mathrm{E}-02$ & $1.00 \mathrm{E}-02$ \\
\cline { 2 - 5 } & & & &
\end{tabular}

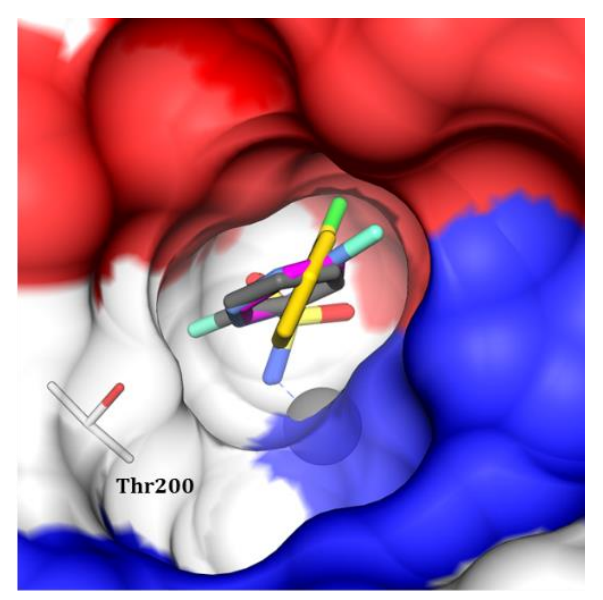

Figure 6. Superposition of CA II/inhibitor adducts: 15 (magenta, PDB 2WEJ), 18 (yellow, PDB 2WEH), 19 (gray, PDB 2WEG) and 20 (blue, PDB 2WEO). Residues delimiting the hydrophobic half are in red, the hydrophilic ones are in blue. Calorimetric data of 15, 18-20 $\left([\mathrm{a}]=\mathrm{kcal} \mathrm{mol}^{-1}\right)^{[47]}$ and kinITC data of 15 and fluorinated compounds $\mathbf{1 9}$ and $\mathbf{2 0}$ bound to CA II. ${ }^{[48]}$

Kinetic data revealed fluorine in $\mathbf{2 0}$ to induce modest dissociation $\left(\mathrm{k}_{\text {off }}\right)$ and large association $\left(\mathrm{k}_{\mathrm{on}}\right)$ values, which are highly influenced by the hydration state of the enzyme cavity ${ }^{[47-50]}$ and by the hydrophobic features of the ligand, ${ }^{[51,52]}$ respectively. As for the former, a striking example is the introduction ad hoc of fluorine substitutions within the benzothiazole scaffold of $\mathbf{2 1}$ for assessment of the $\Delta H / \Delta \mathrm{S}$ compensation phenomenon on CA II. ${ }^{[49-51]}$ (Figure 7).
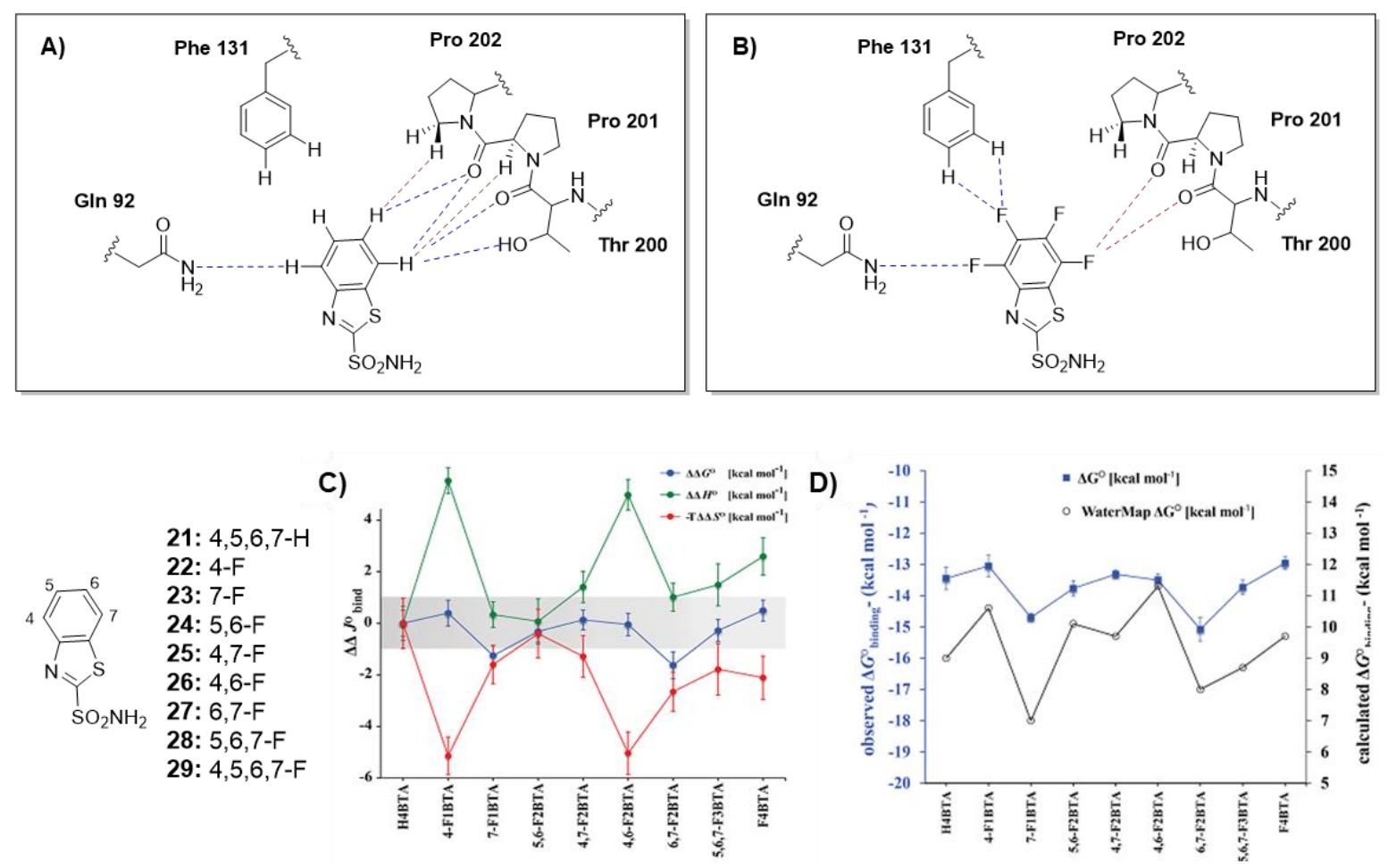

Figure 7. A) Diagram of the amino acid residues of CA forming contacts with the benzothiazole $\left(\mathrm{H}_{4} \mathrm{BTA}, 21\right)$; B) perfluorobenzothiazole $\left(\mathrm{F}_{4} \mathrm{BTA}, 29\right)$. Favorable ligand-protein interactions are represented with a blue 
dashed line, unfavorable with a red dashed line; C) Diagram of the thermodynamic results for $\Delta \Delta \mathrm{J}^{\circ}$ bind (compared to $\mathrm{H}_{4} \mathrm{BTA}$ ) where $J=G$ (blue), $H$ (green), and $S$ (red), obtained from ITC measurements at 298.15 $\mathrm{K}$. To account for differences in the $\mathrm{pKa}$ of each ligand, the measured thermodynamic parameters were corrected to represent the binding of the sulfonamide anion $\left(\mathrm{Ar}-\mathrm{SO}_{2} \mathrm{NH}^{-}\right)$to hCA $\left(\mathrm{hCA}-\mathrm{ZnII}-\mathrm{OH}^{2+}\right)$, allowing to compare the thermodynamic binding parameters of different ligands in a scheme that is independent of their $\mathrm{pKa}$ values (pKa -corrected thermodynamic results). The gray region demarcates the $95 \%$ confidence interval (i.e., two standard deviations) of $\Delta \Delta \mathrm{G}^{\circ}$ bind for $\mathrm{H}_{4} \mathrm{BTA} 21$; D) WaterMap calculations for $\Delta \mathrm{G}^{\circ}$ bind. ${ }^{[49]}$

As expected, the binding geometry as well as the free binding energy for $\mathbf{2 1 - 2 6}$ and $\mathbf{2 8}, \mathbf{3 0}$ were found relatively unchanged and were all ascribed to the compensation effect of the thermodynamic features from the ligands surrounding waters (Figure 7C, D). The higher CA II binding affinity of $\mathbf{2 7}$ was justified with a remarkable entropic contribution due to the ligand desolvation effect. Overall, such an approach is by far the best tool for $\mathrm{k}_{\text {off }}$ determining parameters as it allows to alter considerably the ligand dipole moment without affecting its size, and this in turn heavily affects its interactions with surrounding residues, including waters. ${ }^{[49]}$ As for the $\mathrm{k}_{\mathrm{on}}$ regulating features, combination of experimental and in silico techniques (i.e. SPR, X-ray crystallography, metadynamics, DFT calculations) gave evidence for a "pre-binding" stage which benefits from favourable interactions established between the apolar portions of the ligand with the CA II hydrophobic wall section. ${ }^{[51,52]}$ Such a mechanism also applies to the primary sulfonamide which is being deprotonated only when the distance between its terminal $\mathrm{NH}_{2}$ and the enzymatic zinc (II) ion is in the $2.50-2.75 \AA$ range.

Thus skilful introduction of fluorine(s) within benzene sulfonamide CAIs represents unique means to properly tune $\mathrm{k}_{\mathrm{on} / \mathrm{off}}$ ligand parameters towards $\mathrm{CA}$ isoforms worth of biomedical consideration. ${ }^{[48,52,53]} \mathrm{A}$ remarkable application of this strategy was conducted by Ilies et al on a series of mono/di-substituted sulfanilamide derivatives 30-40 kinetically profiled on both CA II and IX isoforms. (Figure 8). ${ }^{[54]}$

\begin{tabular}{l|cc}
\hline & \multicolumn{2}{c}{$K_{I}(\mathrm{nM})$} \\
\hline & hCA II & hCA IX \\
\hline 30: $X=$ H, $Y=$ H & 300 & 294 \\
31: $X=F, Y=H$ & 60 & 245 \\
32: $X=$ Cl, $Y=$ H & 110 & 264 \\
33: $X=$ Br, $Y=$ H & 40 & 269 \\
34: $X=I, Y=H$ & 70 & 285 \\
\hline
\end{tabular}

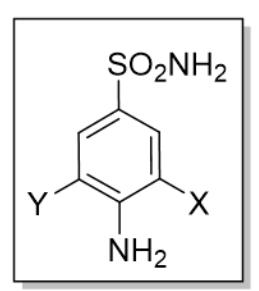

\begin{tabular}{l|cc}
\hline & \multicolumn{2}{c}{$\mathrm{K}_{l}(\mathrm{nM})$} \\
\hline & hCA II & hCA IX \\
\hline 35: $\mathrm{X}=\mathrm{F}, \mathrm{Y}=\mathrm{Cl}$ & 32 & 12 \\
\hline 36: $\mathrm{X}=\mathrm{F}, \mathrm{Y}=\mathrm{Br}$ & 33 & 60 \\
37: $\mathrm{X}=\mathrm{F}, \mathrm{Y}=\mathrm{I}$ & 29 & 34 \\
38: $\mathrm{X}=\mathrm{Cl}, \mathrm{Y}=\mathrm{Cl}$ & 50 & 27 \\
\hline 39: $\mathrm{X}=\mathrm{Cl}, \mathrm{Y}=\mathrm{Br}$ & 54 & 33 \\
40: $\mathrm{X}=\mathrm{Cl}, \mathrm{Y}=\mathrm{I}$ & 61 & 63 \\
\hline
\end{tabular}

Figure 8. Mono/di-halogenated sulfonamides 30-40 and $\mathrm{K}_{I}$ values against CA II and IX. ${ }^{[54]}$

As previously observed for compound $\mathbf{2 0}$, the insertion in $\mathbf{3 0}$ of a fluorine in meta position significantly impact ligand/protein interaction as shown by lower $\mathrm{K}_{I}$ values against the CA II for compound $\mathbf{3 1}$. However, either $\mathrm{Br}(\mathbf{3 3})$ or I (34) were able to induce similar $\mathrm{K}_{I}$ reduction on CA II, thus meaning the halogen impact on 
the binding of such ligands is not limited to fluorine. Less differences between the unsubstituted $\mathbf{3 1}$ and monohalogenated 31-34 were observed for inhibition of the tumor associated CA IX. Introduction of an additional halogen in position 5 of the aryl moiety (i.e. 35-40) determined remarkable reduction of whole $\mathrm{K}_{I}$ values with major effects on the isoform IX. The most potent CA IX inhibitor was the 3-F,5-Cl (35) with a $\mathrm{K}_{I}$ of $12 \mathrm{nM}$, thus 20.4-fold more potent when compared to the mono halogenated precursor $31\left(\mathrm{~K}_{I} 245 \mathrm{nM}\right)$. Specifically, the impact of the fluorine on CA II was clearly observed in 35-37 as lower and close matching $\mathrm{K}_{I}$ values were obtained when compared to those of 38-40 lacking such an element. As for the CA IX, compounds 35-37 showed slightly enhanced differences among each other when compared to their monosubstituted precursors 32-34. ${ }^{[54]}$ Such an outcome can be explained invoking the lower cost for desolvation upon binding of fluorinated ligands when compared to either hydrogen or differently halogenated compounds, more prone to establish halogen bonds when compared to fluorine. ${ }^{[55,56]}$ Moreover, the introduction of one fluorine atom within an halogenated compound involved in an halogen bond interaction is reported to enhance the strength of such bond, increasing the whole binding affinity. ${ }^{[57]}$ The lack of crystallographic data for these compounds makes not trivial the elucidation of the possible contributions to the binding played by fluorine.

Further increase of molecular complexity was reported by Scott et al. which extended the ortho-19 and meta20 by appending a 4-benzylamide tail. (Figure 9). ${ }^{[47]}$
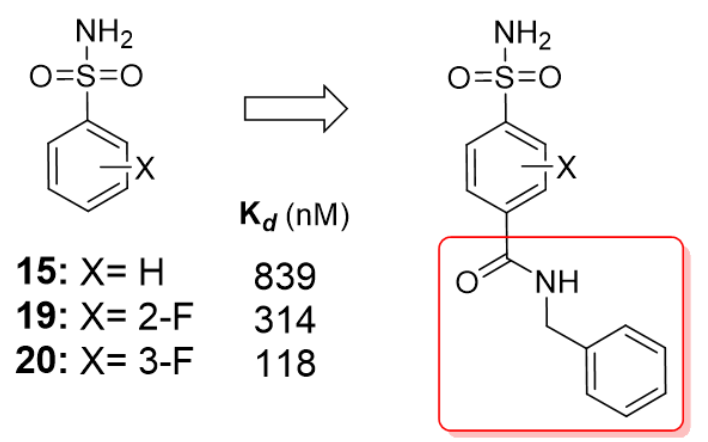

\begin{tabular}{l|c|c|c|c|}
\multicolumn{1}{l}{} & \multicolumn{1}{c}{$\Delta \mathbf{G}^{[\mathrm{a}]}$} & \multicolumn{1}{c}{$\Delta \mathrm{H}^{[\mathrm{a}]}$} & \multicolumn{1}{c}{$-\mathbf{T} \Delta \mathbf{S}^{[\mathrm{a}]}$} & \multicolumn{1}{c|}{$\mathbf{K}_{\mathrm{d}}(\mathbf{n M})$} \\
\cline { 2 - 5 } 41: $\mathrm{X}=\mathrm{H}$ & -10.3 & -9.7 & 0.6 & 27 \\
\cline { 2 - 5 } 42: $\mathrm{X}=2-\mathrm{F}$ & -11.2 & -13.6 & -2.4 & 5.7 \\
\cline { 2 - 5 } 43: $\mathrm{X}=3-\mathrm{F}$ & -10.5 & -10.7 & -0.2 & 20 \\
\cline { 2 - 5 } & \multicolumn{3}{l}{}
\end{tabular}

Figure 9. Structural extension of 15,19 and 20 to give 41,42 and 43 and their CA II thermodynamic binding parameters $\left([\mathrm{a}]=\mathrm{kcal} \mathrm{mol}^{-1}\right) .{ }^{[47]}$

In this case, thermodynamic signatures revealed that fluorine insertion in meta position (43) led to a weaker CA II inhibitor $\left(K_{d}=20 \mathrm{nM}\right)$ when compared to its ortho regioisomer $42\left(K_{d}=5.7 \mathrm{nM}\right)$. The higher affinity showed by the latter was ascribed to a strong enthalpic gain, likely due to favorable contacts between the halogen and the Thr200 residue, as previously described for 19.

Such an example, although restricted to the CA II isoform, is quite valuable as it closely resembles the synthetic evolution of CAIs usually reported in medicinal chemistry. The use of fluorine to afford an enthalpically dominated chemical precursor (i.e. the ortho-F 19) is only apparently misleading as it turns to the desired thermodynamically optimized ligand as chemical manipulation is pursued which contributes to enrich the entropic gain. ${ }^{[47,58]}$ Extension of such an approach and its application to drive ligands toward specific isoforms is well represented by CAIs $\mathbf{4 4}$ and $\mathbf{4 5}$. The former resulted far more potent as a CA II inhibitor than the fluoro containing one ( $\mathrm{K}_{\mathrm{I}}$ of 50 and $390 \mathrm{nM}$ respectively). 

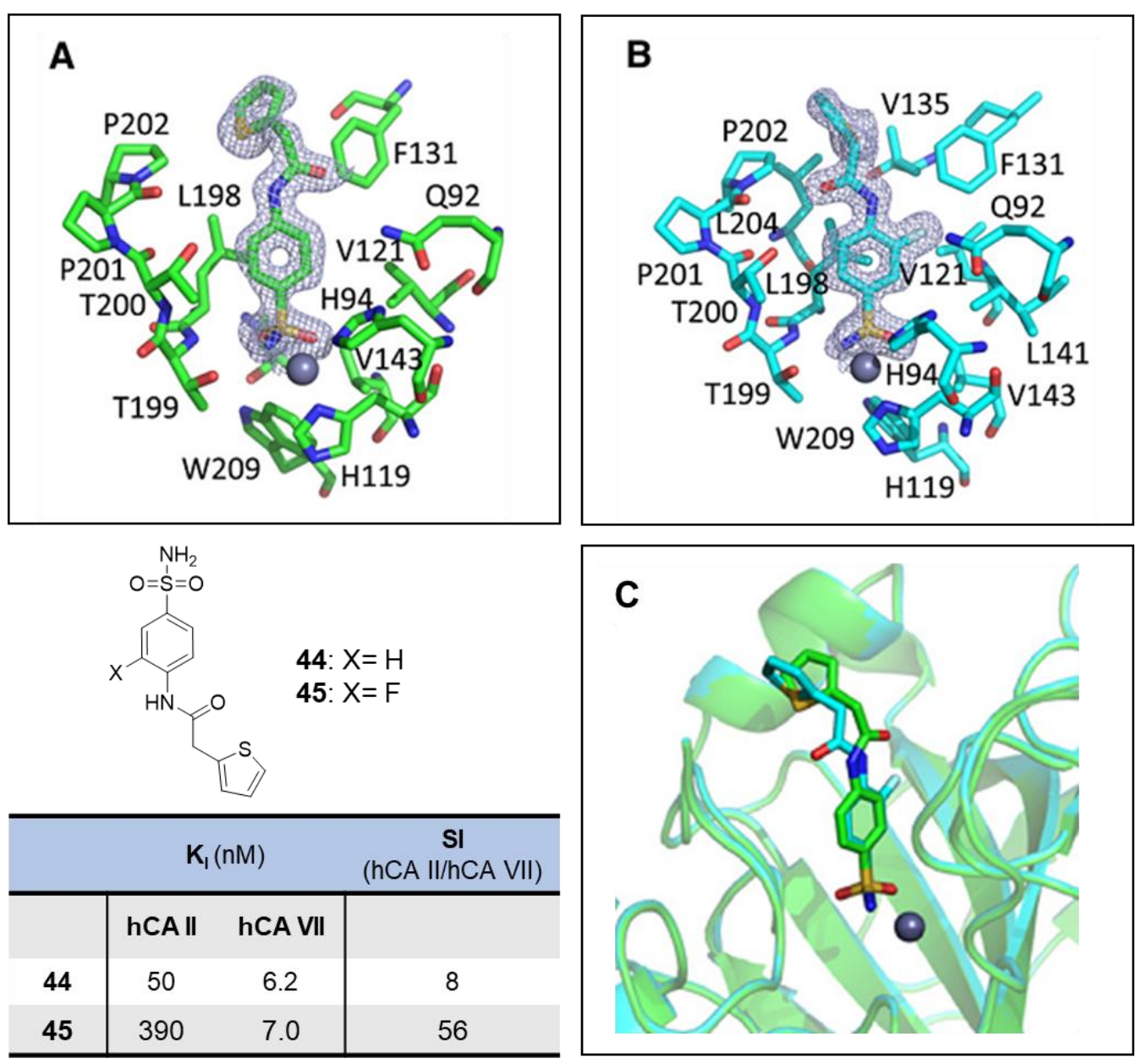

Figure 10. Stick representation of CA II active site in adduct with (A) 44 (green, PDB 3R16) and (B) 45 (cyan, PDB 3R17). The active-site zinc is depicted as a gray sphere. The electron density is represented by a $1.2 \sigma-$ weighted 2Fo-Fc Fourier map (blue mesh). (C) Superposition of CA II complexed with 44 (green) and 45 (cyan). ${ }^{[59]}$

X-Ray crystal structures resolution of their CA II adducts showed the halogen in $\mathbf{4 5}$ induces a nearly $180^{\circ}$ torsion of the tail carbonyl oxygen to point towards Pro202. The thiophene ring was consequently rotated and located in proximity of Pro202 and Val135 (Figure 10). ${ }^{[59]}$ However, the CA II unfavoured fluoro induced conformation in $\mathbf{4 5}$ was not detected for the abundantly expressed CNS CA VII since its $\mathrm{K}_{I}$ value was almost superimposable to the non-halogenated $\mathbf{4 4}$ for the same isoform. This makes such a compounds particularly suitable for the development of CA VII selective inhibitors with biomedical applications. ${ }^{[59]}$

Overall, insertion of fluorine atom(s) on the aromatic/heteroaromatic "head" of sulfonamides CAIs determined multiple effects on binding as it primarily affects the sulfonamide $\mathrm{pKa}$ and the dipole moment of the molecule, with consequences on the binding affinities as well as on the molecule desolvation event within the binding site. Privileged position is the meta, as interactions of the fluorine with the hydrophobic pocket of the active site are thus favored, which in turn lower the $\mathrm{K}_{\mathrm{I}}$ values. The ortho fluorine regioisomers resulted particularly advantageous for ensuring high inhibitory potency for ligands developed during the optimization process by means of tail chemical manipulation. In this case, the halogen resulted particularly effective in increasing the enthalpic gain. Skillful insertion of the fluorine within the ligands aromatic head represents a 
validated strategy for driving the ligand toward preferential CA isoforms as usually multiple halogenation fails to confer enhanced features.

\subsection{Fluorine on "aliphatic tail"}

CAIs bearing fluoroalkyl tails, as in Figure 11, generally show slightly enhanced CA affinities (5.6 to $70 \mathrm{nM}$ variation of $\mathrm{K}_{\mathrm{d}}$ ) when compared to their corresponding hydrocarbon analogues. Such an effect was mainly ascribed to larger hydrophobic surface areas desolved upon ligand binding. ${ }^{[60,61]}$ Compounds of this kind still preserve the canonical binding mode within the CA II, with the tail being associated with the enzymatic hydrophobic wall section (Figure 11C). Thus thermodynamic signatures between alkyl and fluoroalkyl derivatives are very close, with the only exception being the longest fluoroalkyl 46, $(X=F, n=4)$ which showed the smallest $\Delta \mathrm{H}$ value among the fluorinated ligands. ${ }^{[61]}$ In this compound, the terminal $\mathrm{CF}_{3}$ induced the Gln136 side chain to adopt a gauche conformation (Figure 11D). Overall, the desolvation effects on tails (greasy or not) and the hydrophobic interaction with the enzymatic wall were found the main determinants in thermodynamics of binding. Molecular basis for tuning up the ligand affinity by means of surface area increase of the tail is therefore similar for alkyl and fluoroalkyl CAI series, thus substituents other than fluorine may be potentially considered. ${ }^{[61]}$ Considering the recent studies conducted by Klebe's group on alkyl substituted CAIs, ${ }^{[52,53]}$ it can be presumed that the insertion of a perfluoroalkyl tail on the benzenesulfonamide scaffold to give compounds of the type in Figure 11 could be favourable for the binding kinetics, ensuring more contacts with the hydrophobic patch in the "pre-binding" stage, but experimental data are needed to support this hypothesis. ${ }^{[61]}$
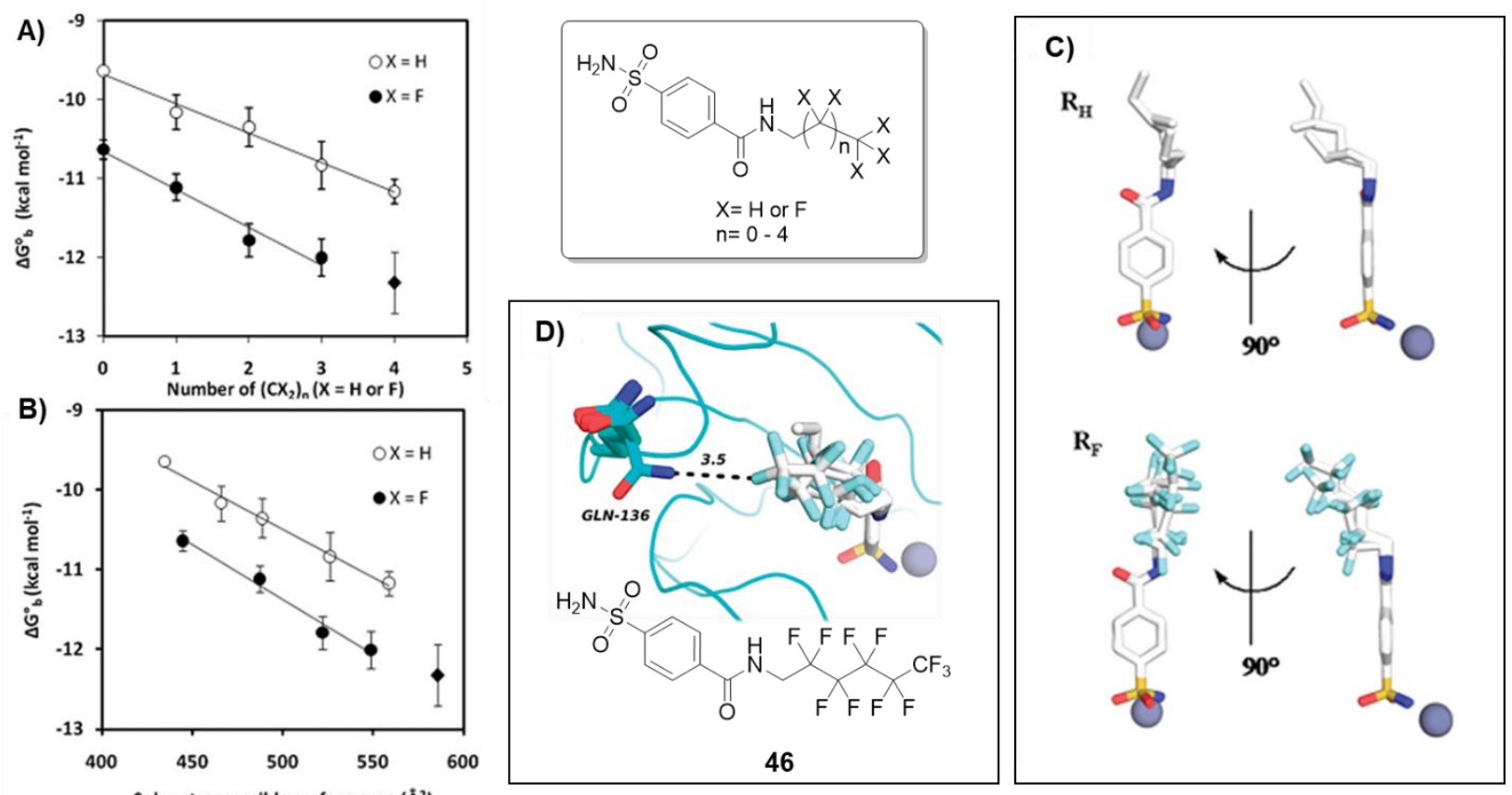

Figure 11. Dependence of $\Delta \mathrm{G}^{\circ}$ for binding of ligands with alkyl (०) and fluoroalkyl (•) tails $(\mathbf{A})$ and on their solvent-accessible surface area in the fully extended conformation $(\mathbf{B})$; $\mathbf{C})$ Aligned structures for 10 ligands determined by X-ray crystallography; D) Crystal structures of fluorinated "greasy tails" complexed with CA 
II. The distance between Gln136 and one fluorine atom of the ligand (RF, $n=4$, compound 46) appears as a dashed line with its length labelled in angstroms. ${ }^{[61]}$

Perfluorooctanoic acid 47 (PFOA), perfluorooctanesulfonic acid 48 (PFOS) and perfluorooctanesufonamide 49 (PFOSA) were investigated in vitro for their inhibitory activity against various CAs and their binding affinities (for CAs I and II) were also assessed by means of native mass spectrometry (MS). The binding modes of $\mathbf{4 7 - 4 9}$ within CA II and IX were investigated in silico (Figure 12). ${ }^{62]}$
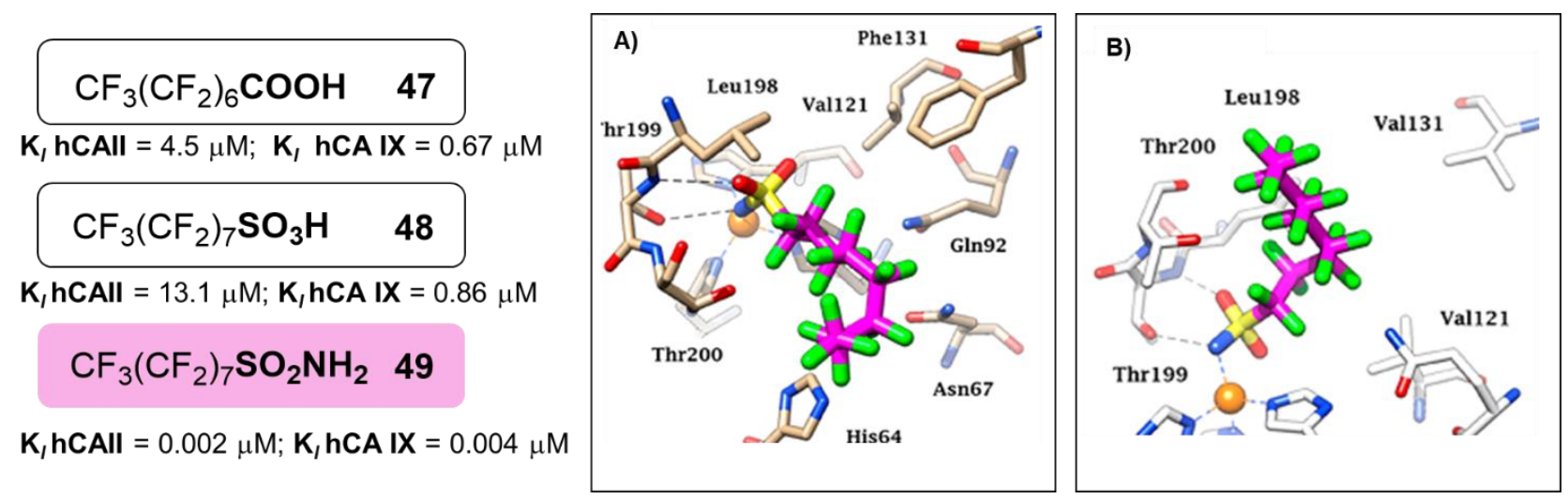

Figure 12. $\mathrm{K}_{I}$ values against $\mathrm{CA}$ II and IX for compounds 47-49 and proposed binding mode of perfluorooctanesulfonamide 49 in CA II (A) and CA IX (B). ${ }^{[2]}$

Calculations showed the PFOSA 49 perfluoroalkylated tail oriented differently within the CA clefts, with a more favorable accommodation for the isoform II. However such differences didn't suit the experimental inhibition potencies ( $\mathrm{K}_{I} \mathrm{~s}$ of 2 and $4 \mathrm{nM}$ for CA II and IX respectively) as the sulfonamide accounted for the main contribution to the overall binding potency. ${ }^{[62]} \mathrm{A}$ better agreement between in silico structural analysis and experimental kinetic data were obtained for the "less efficient" CA binders $\mathbf{4 7}$ and 48 as the binding contribution from the chain resulted more appreciable. This opens a promising approach to differentiate CAs by exploiting fluorinated tails with non-zinc binding inhibitors. In this context a selection of primary, secondary and tertiary benzenesulfonamides containing fluorinated moieties on aliphatic chains were investigated in vitro as potential CAIs (compounds 50-62 in Figure 13). ${ }^{[63,64]}$ The $\beta$-fluoro aniline in 51 strongly enhanced the inhibition potency of its allyl precursor $\mathbf{5 0}$ against CA II and IX and also resulted fairly more potent than the cyclic derivative 52. ${ }^{[63]}$ Among the secondary sulfonamides, the $\beta$-fluorine moiety showed appreciable inhibition data only for $\mathbf{5 5}$ and the gem-fluorinated $\mathbf{5 7}$ with $\mathrm{K}_{I}$ values in the medium nanomolar range. Interestingly, gem-fluorinated showed to be largely more potent than the fluoro-chloro analogue $\mathbf{5 6 .}$ Translocation of the halogen(s) substituents to the adjacent $\gamma$-position (i.e. 58, 59) brought the $K_{I}$ values up the micromolar range. ${ }^{[63]}$ Even more interesting are the tertiary $\beta$-fluorinated sulfonamide 61-62 as showed good potency and selectivity for the tumor associated isoform IX over the widespread isoform CA II. All such examples gave first evidences of the $\beta$-fluorinated amine/sulfonamide moiety on CAIs and its effects on 
kinetics also when inserted within tertiary sulfonamides which mode of inhibition still remains to be determined. ${ }^{[4,65]}$ At this stage, it may be suggested that a gauche conformational effect of this unique $\beta$ fluorinated (or difluorinated) amine/sulfonamide core could account for a privileged orientation of the molecule in the active site.
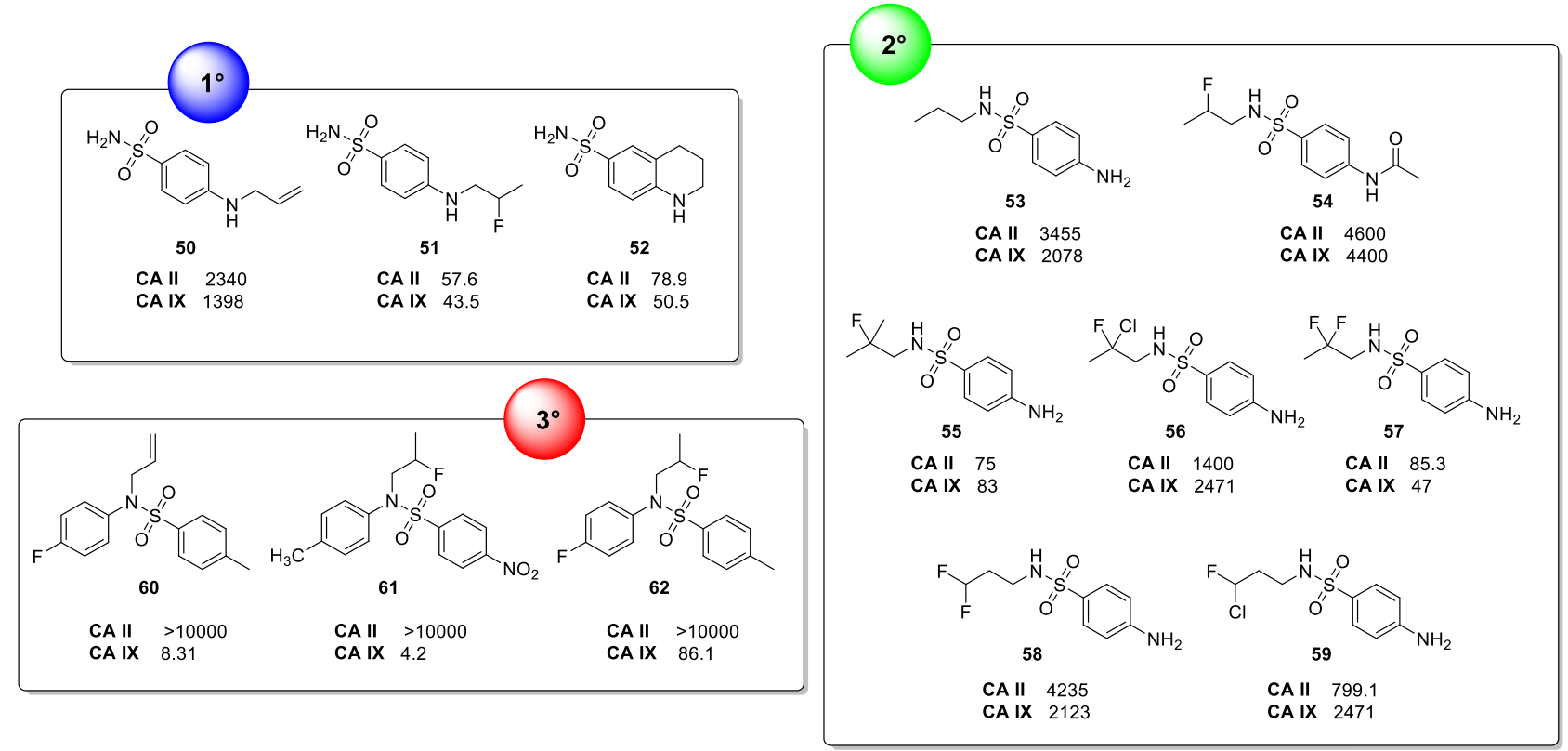

Figure 13. CA II and IX and inhibition values of sulfonamides 50-62. $\mathrm{K}_{I}$ values are in nM. ${ }^{63,64]}$

\subsection{Fluorine on "aromatic tail"}

Binding and structural studies using the $N$-(4-sulfamylbenzoyl)benzylamine (SBBs) bearing fluorinated aromatic tails as model, allowed to explore the different interactions established within the CA II cleft and F131V-CA mutant (Figure 14). Electron density calculations on the unsubstituted benzyl tail in SBB 41 showed a negative charge distribution on both sides of the ring plane, with a positive electrostatic potential contouring its peripheral area. This allows a quadrupole-quadrupole interaction between any perfluorinated benzyl ring and the Phe131 in CA II to be studied. Aromatic moieties of reversed quadrupoles prefer to interact with each other in face-face stacked geometries. ${ }^{[66]}$ A known example is the stacking of benzene and perfluorobenzene which displays nearly identical values in their quadrupole moments, but with opposite signs. ${ }^{[67,68]}$ The small molecule 1:1 co-crystal structures of benzene and hexafluorobenzene exhibit a kind of edge-to-face arrangement alternating parallel stacking of benzene and hexafluorobenzene molecules with their planes separated by about $3.5 \AA^{[69,70]}$ due to the orientation of bond dipoles towards the quadrupole moments. ${ }^{[71,72]}$ The impact of temperature on these interactions and the ability to finely model these interactions are still under discussions. ${ }^{[68,73]}$ Thus, one could have expected that the insertion of the electronegative fluorine(s) in 63-66 could have provoked similar interactions of Phe131 and the fluorinated ligand benzyl tail. $K_{d}$ values of the fluorinated derivatives were progressively lower thus indicating that tighter bindings were established (Figure 14). ${ }^{[74,75]}$ 

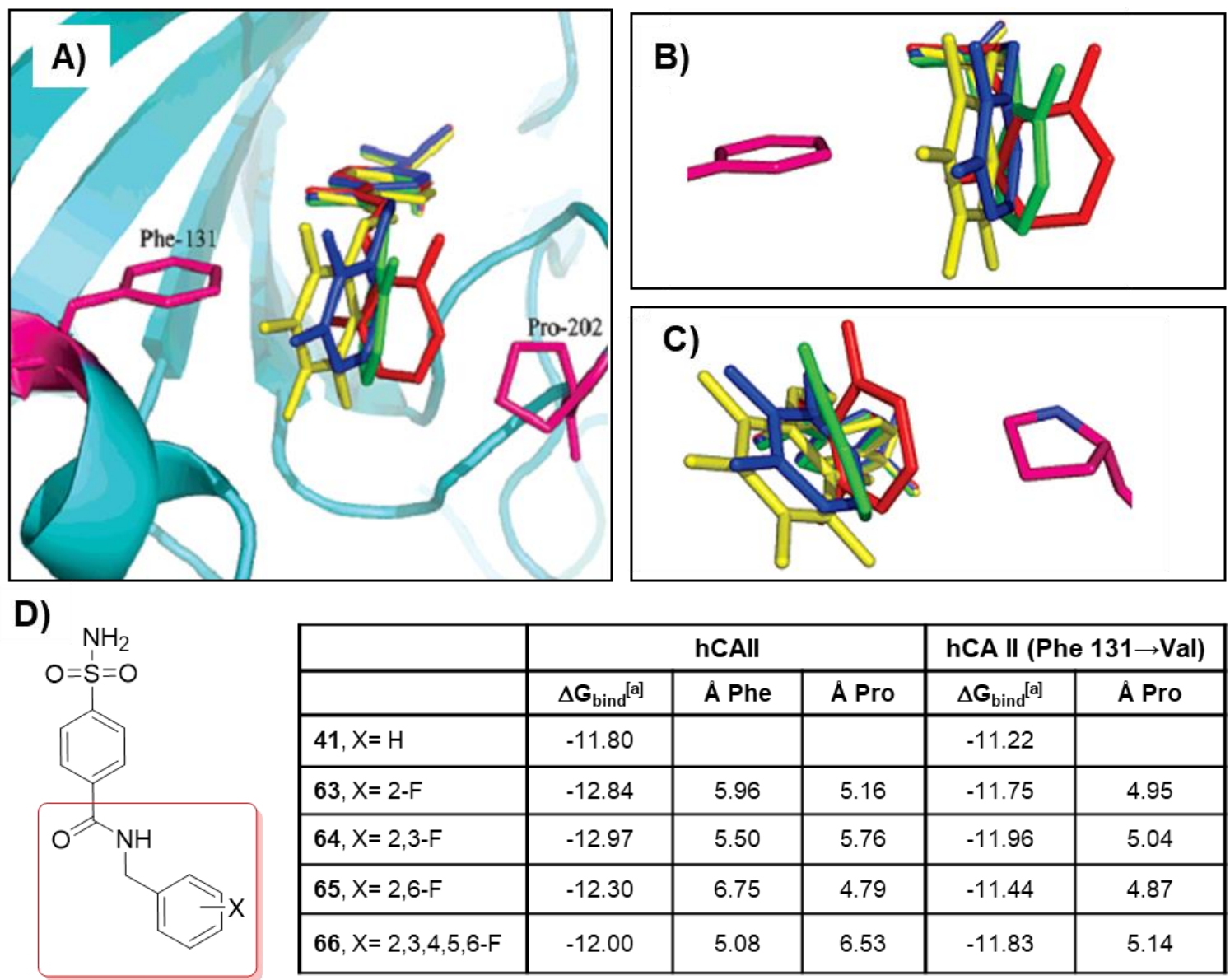

\begin{tabular}{|l|c|c|c|c|c|}
\hline & \multicolumn{3}{|c|}{ hCAll } & \multicolumn{2}{c|}{ hCA II (Phe 131 $\rightarrow$ Val) } \\
\hline & $\Delta \mathbf{G}_{\text {bind }^{[a]}}$ & A Phe & A Pro & $\Delta \mathbf{G}_{\text {bind }^{\text {[a] }}}$ & A Pro \\
\hline $41, X=H$ & -11.80 & & & -11.22 & \\
\hline $63, X=2-F$ & -12.84 & 5.96 & 5.16 & -11.75 & 4.95 \\
\hline $64, X=2,3-F$ & -12.97 & 5.50 & 5.76 & -11.96 & 5.04 \\
\hline $65, X=2,6-F$ & -12.30 & 6.75 & 4.79 & -11.44 & 4.87 \\
\hline $66, X=2,3,4,5,6-F$ & -12.00 & 5.08 & 6.53 & -11.83 & 5.14 \\
\hline
\end{tabular}

[a] $\mathrm{Kcal} / \mathrm{mol}$

Figure 14. A) Superposition of CA II-inhibitor complexes. Inhibitors are color coded as follows: 2-fluoroSBB 63 (green), 2,3-difluoro-SBB 64 (blue), 2,6-difluoro-SBB 65 (red), and 2,3,4,5,6-pentafluoro-SBB 66 (yellow); B) Interaction between Phe131 and 63-66 within CA II; C) Interaction between Pro202 and 63-66 within CAII; A) Fluorine insertion on SBB (41) benzyl group, to give 63-66; Binding energies $(\Delta G)$ and Intercentroid Separation Distances $(\AA)$ for each of the SBB-Phe-131 and SBB-Pro-202 complexes 63-66. ${ }^{[7]}$

However, X-Ray resolution of CA II/63-66 complexes showed an edge-to-face interaction between the centroid of Phe131 and the fluorinated benzyl ring of the ligands (with the exception of $\mathbf{6 5}$ ). The distances were gradually decreased upon fluorination (Figure 14 B and C). For the difluorinated compound 65, the aromatic ring was rotated around the $\mathrm{C}$-phenyl bond to place the fluorine at 2-position close to Phe131, and thus establishing favorable electrostatic interactions with its partially positively charged peripheral area. ${ }^{\text {[74-77] }}$ Dispersive forces engaged the ligands aryl rings and Pro202, with the 2-fluorine 63 being the most involved (Figure 14 C) ${ }^{[74]}$ Such evidences pointed out the important role of dispersive interactions within the CA II other than the canonical one with Phe131. This was more evident in the F131V CA mutant which lacks that residue (Figure S1 A and B). ${ }^{[77]}$ Here, pairwise decomposition of residue interaction energies, accounted for the distances between the Thr199 residue and the sulfonamide moiety, being the real determinant for diverse $\mathrm{K}_{\mathrm{d}}$ values within the fluorinated series (Figure S1 C) ${ }^{\left[{ }^{[7]}\right.}$ Such an effect is integrated with $p K_{a}$ lowering effects in fluorine substituted ligands, which further contributes to the inhibitory potency. ${ }^{[75]}$ These results clearly 
evidence the ability of (per)fluorinated aromatic tail to strongly impact on potency and selectivity for these inhibitors through a combination of $\mathrm{pKa}$ lowering effect and finely tuned dispersive interactions.

The influence of aromatic fluorinated tails on ligand's physicochemical features has also been widely explored, as in the case of AAZ 1 and BZA 3 ${ }^{[78,79]}$ Although the perfluoroarylsulfonyl/carbonyl aromatic tails did not affect the in vitro inhibitory profiles of such compounds when compared to $\mathbf{A A Z}$ and $\mathbf{B Z A}$, they proved to be potent IOP-lowering agents due to proper LogPs. ${ }^{[78]} \mathrm{X}$-ray crystallography of the CA II/67 adduct revealed stacking interactions between the perfluorophenyl ring of the ligand and Phe 131 (Figure 15). ${ }^{[8]}$ Moreover, an ortho fluorine atom of the perfluorobenzoyl tail was involved in a complex H-bond network also including the exocyclic nitrogen atom of the ligand and two water molecules (Wat 1194 and Wat 1199). These additional interactions contributed to the stabilization of the inhibitor within the enzymatic site, thus fitting the lower $\mathrm{K}_{\mathrm{I}}$ values observed for PFMZ 67 when compared to MZA ( $\mathrm{K}_{\mathrm{I}}=1.5$ and $14 \mathrm{nM}$ respectively).
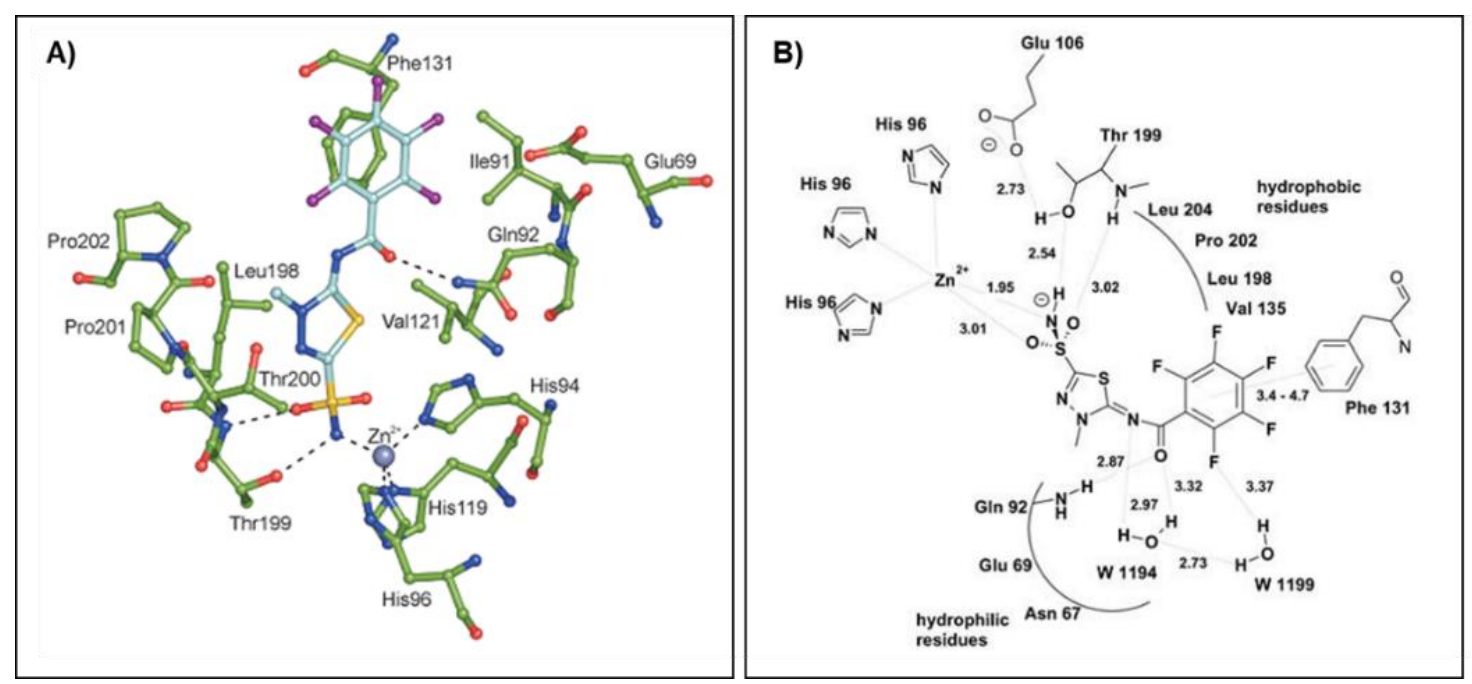

Figure 15. A) CA II/67 complex showing the zinc ion coordination, hydrogen bonds and residues participating in the van der Waals interactions with the inhibitor scaffold (distance $<4.5 \AA$ ). B) Schematic representation of PFMZ 67 binding to the CA II active site (numbers represent distances in $\AA$ ). ${ }^{[21,80]}$

The strong electrophilic character of the para $s p^{2}$-carbon bearing the fluorine makes such a position a preferential site for nucleophilic substitutions to take place, and opened the way for substrates lacking the halogen (i.e. 68, 69, Figure 16) or bearing appropriate linkers with the intent to disfavor undesired tautomeric structures (i.e. 70, 71, Figure 16). ${ }^{[79,81-83]}$ In vitro inhibition profiling revealed these compounds as very potent inhibitors of the tumor associated CA IX, particularly for the ureido derivative 71. ${ }^{[22,84]}$ 


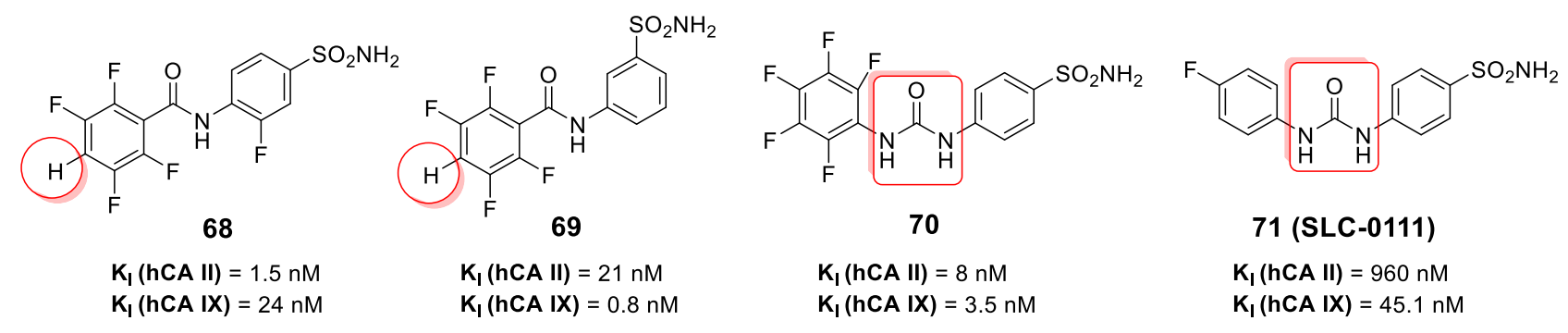

Figure 16. Fluorine-containing inhibitors devoid of enhanced reactivity with thiols. ${ }^{[79,81-83,85]}$

Compound $\mathbf{7 1}$ is in Phase 1b/II clinical trials as CA IX inhibitor in association with gemcitabine for the treatment of hypoxic solid tumors. The role of fluorine is mainly to endow the ligand with proper pharmacokinetic and pharmacodynamic features rather than driving CA inhibitory potency or isoform selectivity, although X-Ray studies showed the larger cavity of CA IX to better accommodate $\mathbf{7 1}$ tail within the hydrophobic pocket created by Val131 and Gly132, thus leading to more efficient hydrophobic interactions to take place when compared to CA II (Figure S2). ${ }^{[55-89]}$

\section{CAIs and ${ }^{19}$ F NMR}

${ }^{19} \mathrm{~F}$ Nuclear Magnetic Resonance (NMR) spectroscopy is a very reliable and sensitive technique to study the protein-ligand binding features. ${ }^{[90,91]}$ Since this element is rare in biological systems it offers several advantages when compared to usually explored nuclei (i.e. ${ }^{1} \mathrm{H},{ }^{15} \mathrm{~N}$ and ${ }^{13} \mathrm{C}$ ) and perfectly suits as bioorthogonal element when retrieving molecular interactions. ${ }^{[00,92,93]}$ In particular ${ }^{19} \mathrm{~F}-\mathrm{NMR}$ possesses: $i$ ) high sensitivity (83\% relative to ${ }^{1} \mathrm{H}-\mathrm{NMR}$ ) and $100 \%$ isotopic natural abundance; $i$ ) wide dispersion chemical shifts (> 300 ppm range) and iii) large Chemical Shift Anisotropy (CSA). Overall ${ }^{19}$ F-NMR makes use of the high sensitivity of the nucleus to electronic and magnetic environmental changes coupled to wide signals spreading in the ppm scale. ${ }^{[90,92-94]}$ Noteworthy is the "rule of shielding" which correlates ${ }^{19} \mathrm{~F}$ chemical shift values, to the nature of contacts established (i.e. hydrogen bond/dipolar interactions or hydrophobic contacts) (Figure S3). ${ }^{[95]}$ Two complementary approaches are largely used in NMR spectroscopy: 1) the ligand based and 2) the protein based methods (Figure S4 a and b). ${ }^{[92,93]}$ Ligand-observed NMR is a fast and easy technique, which doesn't require protein labelling neither high concentrations of ligand (i.e. $<10 \mu \mathrm{M}$ ) and allows to evaluate various inhibitors at the same time. ${ }^{[45,92]}$ An example of protein-observed NMR with CA was reported by Gerig, using fluorophenylalanine as modified residue (Figure S4 b). ${ }^{[96]}$

A recent and successful example of selective aminoacidic chemical modification on CAs applied to NMR protein detection is referred as the ligand-directed tosyl (LDT) approach, aimed to selectively label a protein with a desired probe within its native environment (Figure 17). ${ }^{[97]}$ The same authors also performed CA I labeling within Red Blood Cells (RBC) thus opening new opportunities for the in cell NMR screening of CAIs. ${ }^{[98]}$ 

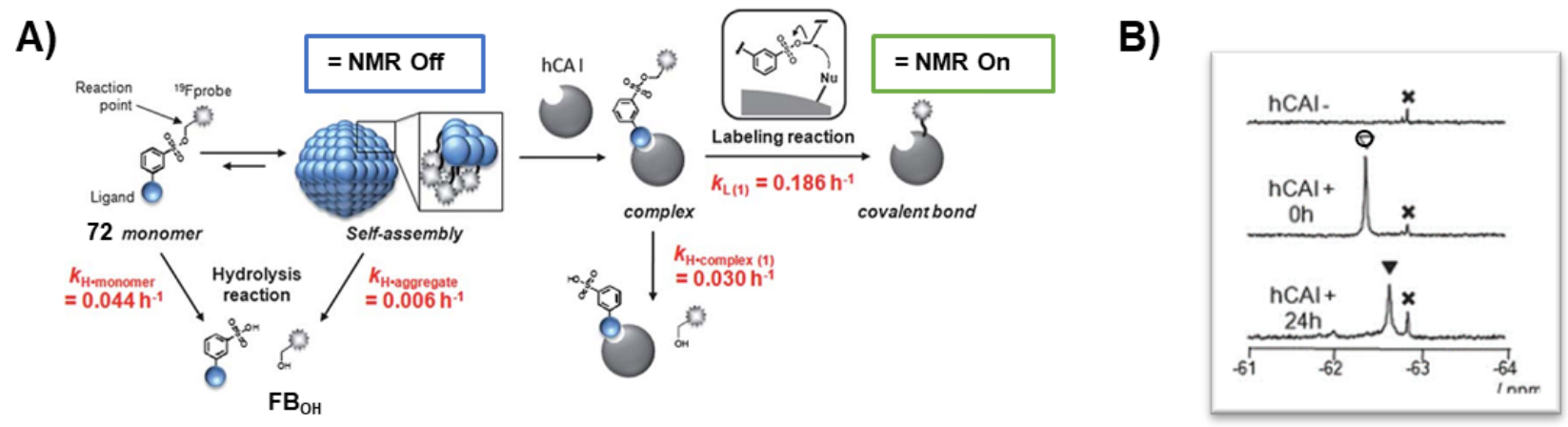

Figure 17. A) Scheme of the self-assembly, hydrolysis and labelling processes in 72-mediated CA I labelling. B) ${ }^{19}$ F-NMR spectra of a reaction mixture during the labelling process; (X) 3,5-bis(trifluoromethyl)benzene derivative $(\mathrm{FB})$-containing fragment $\left(\mathrm{FB}_{\mathrm{OH}}\right)^{\left[{ }^{[97]}\right.}$

An unconventional approach to gather structural information on ligand protein interactions is represented by ${ }^{19}$ F-NMR pseudocontact shift (PCS) analysis. ${ }^{[99]}$ When compared to NOE experiments, PCS drastically reduces the measurement times, also eliminating the need for isotope labelled protein as well as chemical modification of the ligand. As example of ${ }^{19} \mathrm{~F}-\mathrm{NMR}-\mathrm{PCS}$ is reported the use of lanthanide chelating tags bound site-specifically to single cysteine mutants to determine the anisotropy tensors. The measurement of one-dimensional ${ }^{19} \mathrm{~F}$-NMR experiments and analysis of the obtained ${ }^{19} \mathrm{~F}-\mathrm{PCS}$ over a distance range of $22-$ $38 \AA$ A allowed to determine the binding of the fluorinated compounds 64 and 73 within CA II (Figure 18). ${ }^{[99]}$
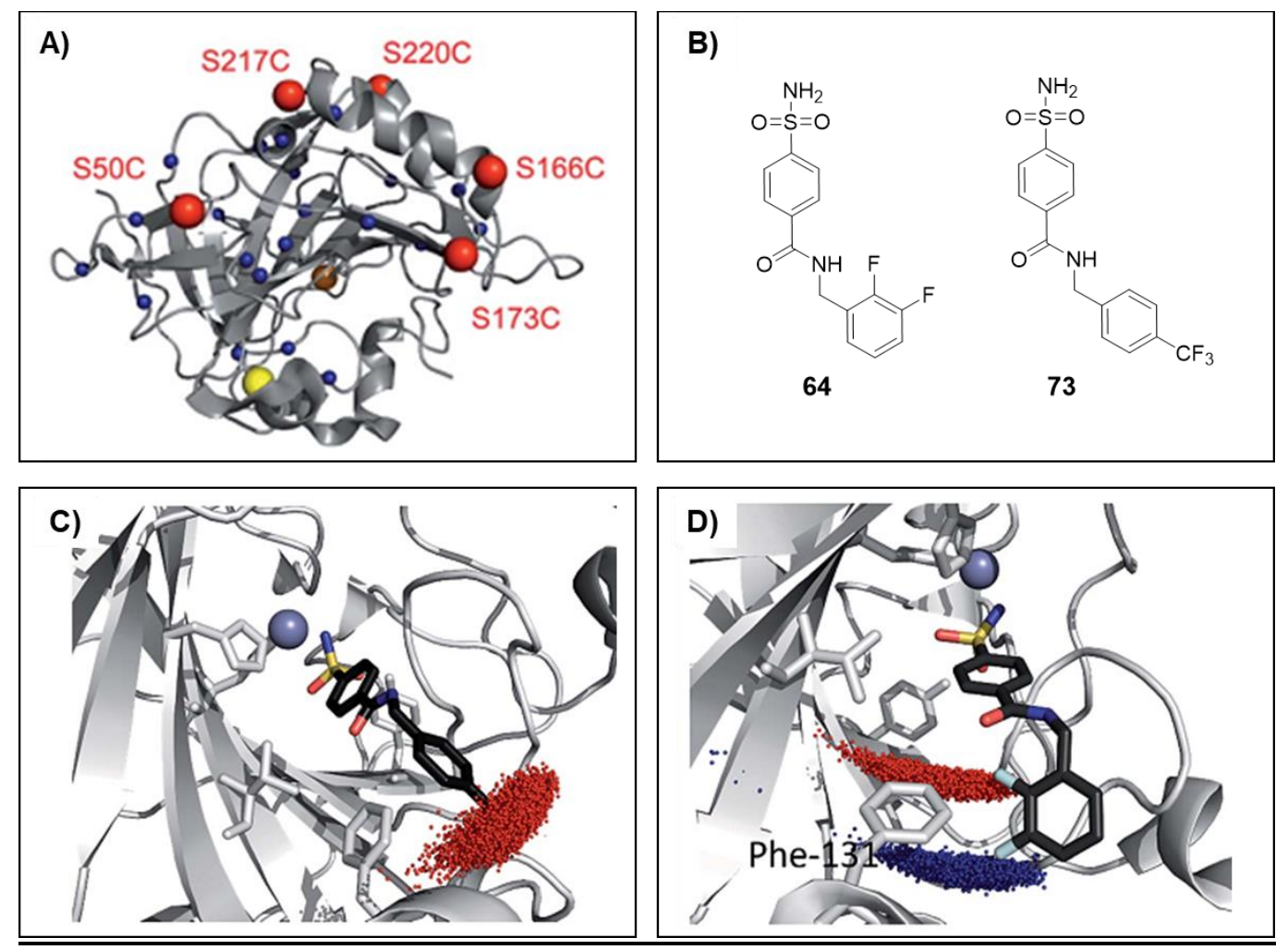

Figure 18. A) X-ray structure of CA II (PDB 3KS3). Red: selected serine to cysteine mutation sites, yellow: native Cys206, blue: leucine residues and orange: zinc ion.; B) Selected ligands for proof-of-principle study; 
C and D) Point cloud of the Monte-Carlo fluorine position calculation for 73 (C) and 64 (D) within CA II; light blue sticks: fluorine atoms, blue sphere: $\mathrm{Zn}^{2+}$ ion. ${ }^{[99]}$

\section{Conclusions}

By selecting specific examples from a wide range of available data on fluorinated CAIs of the sulfonamides type, this review attempts to give a rationale why should we use fluorine in CA ligands and where does such a substitution pattern provide any advantage, but also, where it is detrimental for binding and selectivity. Crystallographic and thermodynamic studies conducted on simple scaffolds helped to rationale how wisely insert fluorine atom(s) within a CAI moiety, in order to precisely enhance or disrupt ligand protein interactions, depending on the location the fluorine substitution is targeted on the ligand. Using benzenesulfonamide CA inhibitors, exhibiting different fluorinated patterns (fluorine atom(s) located on the ring, on the aliphatic or aromatic tails), some "general guidelines" could be summarized as following: 1) For ring-substituted benzenesulfonamide inhibitors, the small size of the fluorine atom and its electronically rich nature allows really specific interactions with a Thr200 residue close the zinc atom when the aromatic ring is ortho substituted with fluorine atom(s), as for e.g. compound 19. Large association and small dissociation constants calculated for meta-F substituted derivatives (i.e. 20) highlighted a special role of fluorine for the binding kinetics when inserted in such position, ensuring an optimal placement and fit of the ligand within the binding pocket. Multiple addition of fluorine atoms did not provide any advantage in terms of free binding energy and thermodynamic signatures, probably because the scaffold of these compounds is too simple and they can adopt a variety of orientation within the active site, "compensating" for the introduction of additional fluorine atoms. ${ }^{[47,48,52,53]}$ Another very interesting impact that can have fluorine insertion in meta positions of the aromatic ring is on the discrimination between hCA isoforms, as shown for compound $\mathbf{4 5}$ showing high selectivity for the CNS expressed CA VII over the widespread isoform II ; ${ }^{[59]} 2$ ) In analogy with alkyl tails, perfluorinated aliphatic tail interaction with the hydrophobic pocket may favor binding kinetics in the prebinding stage and can be envisaged as a strategy to enhance inhibitors potency. ${ }^{[53,61]}$ However, the increased affinity due to the large hydrophobic surface areas desolved upon ligand binding can be potentially obtained with substituents other than fluorine (i.e. alkyl groups). ${ }^{[61]} \beta$-fluorinated amines and sulfonamides can also be seen as a promising specific pharmacophore to specifically interact with one selected isoform, although for this case, the reason for this selectivity remained unclear (e.g. compound 61). ${ }^{[100]} 3$ ) Fluorination of the aromatic tail also strongly impacts the potency and selectivity of the studied inhibitors. This comes from mainly a combination of $\mathrm{pKa}$ lowering effect and finely tuned dispersive interactions. Moreover, perfluroaromatic tail insertion may confer a balanced hydro/lipophilic profile to CAIs, improving their pharmacokinetic properties. It is the case of the anti-glaucoma agent $\mathbf{6 7}$, which showed a very high penetrability through the cornea and a slow elimination, ensuring a long-lasting IOP lowering effect. ${ }^{[78,79,81-83]}$

Overall, the insertion of fluorine on CAIs of the sulfonamide type accounts for a multitude of effects. The increase of molecular complexity of the scaffolds along with the strength of the sulfonamide-zinc coordination, which represents the main contribution to the binding, may shade other interactions mediated by the fluorine 
atom(s). In this context, multiple approaches such as ITC, kinetic and inhibition studies, X-ray crystallography and NMR are useful in dissecting single binding contribution to the overall observed effect. ${ }^{[22,101,102]}$ It makes no doubt that the exploitation of innovative directions made in the field of protein and ligand-based fluorine NMR screening ${ }^{[92,103]}$ will allow to avoid misconduct and finely tune the exploitation of the selective fluorine atom insertion in the future.

\section{$\underline{\text { References }}$}

[1] D. Bégué, J.P., Bonnet-Delpon, Chimie Bioorganique et Médicinale Du Fluor, EDP Science, 2005.

[2] J. Wang, M. Sánchez-Roselló, J. L. Aceña, C. Del Pozo, A. E. Sorochinsky, S. Fustero, V. A. Soloshonok, H. Liu, Chem. Rev. 2014, 114, 2432-2506.

[3] Y. Zhou, J. Wang, Z. Gu, S. Wang, W. Zhu, J. L. Acenã, V. A. Soloshonok, K. Izawa, H. Liu, Chem. Rev. 2016, 116, 422-518.

[4] D. O'hagan, Chem. Soc. Rev. 2008, 37, 308-319.

[5] I. Ojima, J. Org. Chem. 2013, 78, 6358-6383.

[6] I. Ojima, Fluorine in Medicinal Chemistry and Chemical Biology, 2009.

[7] M. Morgenthaler, E. Schweizer, A. Hoffmann-Röder, F. Benini, R. E. Martin, G. Jaeschke, B. Wagner, H. Fischer, S. Bendels, D. Zimmerli, J. Schneider, F. Diederich, M. Kansy, K. Müller, ChemMedChem 2007, 2, 1100-1115.

[8] E. P. Gillis, K. J. Eastman, M. D. Hill, D. J. Donnelly, N. A. Meanwell, J. Med. Chem. 2015, 58, $8315-8359$.

[9] L. E. Zimmer, C. Sparr, R. Gilmour, Angew. Chemie - Int. Ed. 2011, 50, 11860-11871.

[10] X. G. Hu, D. S. Thomas, R. Griffith, L. Hunter, Angew. Chemie - Int. Ed. 2014, 53, 6176-6179.

[11] B. Linclau, Z. Wang, G. Compain, V. Paumelle, C. Q. Fontenelle, N. Wells, A. Weymouth-Wilson, Angew. Chemie - Int. Ed. 2016, 55, 674-678.

[12] J. Graton, Z. Wang, A. M. Brossard, D. Gonçalves Monteiro, J. Y. Le Questel, B. Linclau, Angew. Chemie - Int. Ed. 2012, 51, 6176-6180.

[13] N. S. Keddie, A. M. Z. Slawin, T. Lebl, D. Philp, D. O’Hagan, Nat. Chem. 2015, 7, 483-488.

[14] M. G. Holl, M. D. Struble, M. A. Siegler, T. Lectka, J. Fluor. Chem. 2016, 188, 126-130.

[15] C. Bissantz, B. Kuhn, M. Stahl, J. Med. Chem 2010, 53, 5061-5084.

[16] P. Li, J. M. Maier, E. C. Vik, C. J. Yehl, B. E. Dial, A. E. Rickher, M. D. Smith, P. J. Pellechia, K. D. Shimizu, Angew. Chemie Int. Ed. 2017, 56, 7209-7212.

[17] C. T. Supuran, Nat. Rev. Drug Discov. 2008, 7, 168-181.

[18] C. T. Supuran, Biochem. J. 2016, 473, 2023-2032.

[19] K. S. Smith, C. Jakubzick, T. S. Whittam, J. G. Ferry, Proc. Natl. Acad. Sci. U. S. A. 1999, 96, 15184-15189.

[20] E. L. Jensen, R. Clement, A. Kosta, S. C. Maberly, B. Gontero, ISME J. 2019, 13, 2094-2106.

[21] V. Alterio, A. Di Fiore, K. D’Ambrosio, C. T. Supuran, G. De Simone, Chem. Rev. 2012, 112, 44214468 . 
[22] J. F. Domsic, R. McKenna, Biochim. Biophys. Acta - Proteins Proteomics 2010, 1804, 326-331.

[23] C. L. Lomelino, J. T. Andring, R. McKenna, Int. J. Med. Chem. 2018, 2018, 1-21.

[24] C. T. Supuran, Expert Opin. Ther. Pat. 2018, 28, 709-712.

[25] K. D’Ambrosio, S. Carradori, S. M. Monti, M. Buonanno, D. Secci, D. Vullo, C. T. Supuran, G. De Simone, Chem. Commun. 2015, 51, 302-305.

[26] A. Angeli, D. Tanini, A. Nocentini, A. Capperucci, M. Ferraroni, P. Gratteri, C. T. Supuran, Chem. Commun. 2019, 55, 648-651.

[27] F. Carta, M. Aggarwal, A. Maresca, A. Scozzafava, R. McKenna, C. T. Supuran, Chem. Commun. 2012, 48, 1868-1870.

[28] D. Vullo, M. Durante, F. S. Di Leva, S. Cosconati, E. Masini, A. Scozzafava, E. Novellino, C. T. Supuran, F. Carta, J. Med. Chem. 2016, 59, 5857-5867.

[29] M. Abellán-Flos, M. Tanç, C. T. Supuran, S. P. Vincent, J. Enzyme Inhib. Med. Chem. 2016, 31, 946-952.

[30] A. Di Fiore, A. Maresca, C. T. Supuran, G. De Simone, Chem. Commun. 2012, 48, 8838-8840.

[31] F. Carta, C. T. Supuran, A. Scozzafava, Future Med. Chem. 2014, 6, 1149-1165.

[32] F. Carta, C. Temperini, A. Innocenti, A. Scozzafava, K. Kaila, C. T. Supuran, J. Med. Chem. 2010, $53,5511-5522$.

[33] A. Karioti, F. Carta, C. T. Supuran, Molecules 2016, 21, 1649.

[34] A. Nocentini, C. T. Supuran, Expert Opin. Drug Discov. 2019, 14, 1175-1197.

[35] V. M. Krishnamurthy, G. K. Kaufman, A. R. Urbach, I. Gitlin, K. L. Gudiksen, D. B. Weibel, G. M. Whitesides, Chem. Rev. 2008, 108, 946-1051.

[36] C. T. Supuran, A. Scozzafava, Expert Opin. Ther. Pat. 2000, 10, 575-600.

[37] D. Neri, C. T. Supuran, Nat. Rev. Drug Discov. 2011, 10, 767-777.

[38] C. B. Mishra, S. Kumari, A. Angeli, S. Bua, M. Tiwari, C. T. Supuran, J. Med. Chem. 2018, 61, 3151-3165.

[39] A. Scozzafava, L. Menabuoni, F. Mincione, F. Briganti, G. Mincione, C. T. Supuran, J. Med. Chem. 1999, 42, 2641-2650.

[40] A. Casini, A. Scozzafava, F. Mincione, L. Menabuoni, M. A. Ilies, C. T. Supuran, 2000, 43, 48844892.

[41] T. H. Maren, C. W. Conroy, J. Biol. Chem. 1993, 268, 26233-26239.

[42] K. Håkansson, A. Liljas, FEBS Lett. 1994, 350, 319-322.

[43] C. Temperini, A. Cecchi, N. A. Boyle, A. Scozzafava, J. E. Cabeza, P. Wentworth, G. M. Blackburn, C. T. Supuran, Bioorganic Med. Chem. Lett. 2008, 18, 999-1005.

[44] S. Z. Fisher, L. Govindasamy, N. Boyle, M. Agbandje-McKenna, D. N. Silverman, G. M. Blackburn, R. McKenna, Acta Crystallogr. Sect. F Struct. Biol. Cryst. Commun. 2006, 62, 618-622.

[45] V. M. Krishnamurthy, B. R. Bohall, C. Y. Kim, D. T. Moustakas, D. W. Christianson, G. M. Whitesides, Chem. - An Asian J. 2007, 2, 94-105.

[46] J. C. Biffinger, H. W. Kim, S. G. DiMagno, ChemBioChem 2004, 5, 622-627.

[47] A. D. Scott, C. Phillips, A. Alex, M. Flocco, A. Bent, A. Randall, R. O’Brien, L. Damian, L. H. Jones, ChemMedChem 2009, 4, 1985-1989. 
[48] S. Glöckner, K. Ngo, B. Wagner, A. Heine, G. Klebe, Biomolecules 2020, 10, 509.

[49] B. Breiten, M. R. Lockett, W. Sherman, S. Fujita, M. Al-Sayah, H. Lange, C. M. Bowers, A. Heroux, G. Krilov, G. M. Whitesides, J. Am. Chem. Soc. 2013, 135, 15579-15584.

[50] P. W. Snyder, J. Mecinović, D. T. Moustakas, S. W. Thomas, M. Harder, E. T. Mack, M. R. Lockett, A. Héroux, W. Sherman, G. M. Whitesides, Proc. Natl. Acad. Sci. U. S. A. 2011, 108, 17889-17894.

[51] M. R. Lockett, H. Lange, B. Breiten, A. Heroux, W. Sherman, D. Rappoport, P. O. Yau, P. W. Snyder, G. M. Whitesides, Angew. Chemie Int. Ed. 2013, 52, 7714-7717.

[52] R. Gaspari, C. Rechlin, A. Heine, G. Bottegoni, W. Rocchia, D. Schwarz, J. Bomke, H. D. Gerber, G. Klebe, A. Cavalli, J. Med. Chem. 2016, 59, 4245-4256.

[53] S. Glöckner, K. Ngo, C. P. Sager, T. Hüfner-Wulsdorf, A. Heine, G. Klebe, ACS Chem. Biol. 2020, $15,675-685$.

[54] M. A. Ilies, D. Vullo, J. Pastorek, A. Scozzafava, M. Ilies, M. T. Caproiu, S. Pastorekova, C. T. Supuran, J. Med. Chem. 2003, 46, 2187-2196.

[55] J. Fanfrlík, F. X. Ruiz, A. Kadlčíková, J. Řezáč, A. Cousido-Siah, A. Mitschler, S. Haldar, M. Lepšík, M. H. Kolář, P. Majer, A. D. Podjarny, P. Hobza, ACS Chem. Biol. 2015, 10, 1637-1642.

[56] P. Auffinger, F. A. Hays, E. Westhof, P. S. Ho, Proc. Natl. Acad. Sci. U. S. A. 2004, 101, 1678916794.

[57] J. Fanfrlík, M. Kolář, M. Kamlar, D. Hurný, F. X. Ruiz, A. Cousido-Siah, A. Mitschler, J. Řezáč, E. Munusamy, M. Lepšík, P. Matějíček, J. Veselý, A. Podjarny, P. Hobza, ACS Chem. Biol. 2013, 8, 2484-2492.

[58] G. Klebe, Nat. Rev. Drug Discov. 2015, 14, 95-110.

[59] S. Biswas, M. Aggarwal, Ö. Güzel, A. Scozzafava, R. McKenna, C. T. Supuran, Bioorganic Med. Chem. 2011, 19, 3732-3738.

[60] J. Gao, S. Qiao, G. M. Whitesides, J. Med. Chem. 1995, 38, 2292-2301.

[61] J. Mecinović, P. W. Snyder, K. A. Mirica, S. Bai, E. T. MacK, R. L. Kwant, D. T. Moustakas, A. Héroux, G. M. Whitesides, J. Am. Chem. Soc. 2011, 133, 14017-14026.

[62] G. T. H. Nguyen, A. Nocentini, A. Angeli, P. Gratteri, C. T. Supuran, W. A. Donald, Anal. Chem. 2020, $92,4614-4622$.

[63] G. Compain, A. Martin-Mingot, A. Maresca, S. Thibaudeau, C. T. Supuran, Bioorganic Med. Chem. 2013, 21, 1555-1563.

[64] B. Métayer, A. Mingot, D. Vullo, C. T. Supuran, S. Thibaudeau, Chem. Commun. 2013, 49, 60156017.

[65] L. Hunter, Beilstein J. Org. Chem. 2010, 6, 38-38.

[66] J. H. Williams, Acc. Chem. Res. 1993, 26, 593-598.

[67] M. R. Battaglia, A. D. Buckingham, J. H. Williams, Chem. Phys. Lett. 1981, 78, 421-423.

[68] A. F. Tillack, B. H. Robinson, J. Phys. Chem. B 2017, 121, 6184-6188.

[69] C. R. Patrick, G. S. Prosser, Nature 1960, 187, 1021.

[70] J. H. Williams, J. K. Cockcroft, A. N. Fitch, Angew. Chemie Int. Ed. English 1992, 31, 1655-1657.

[71] J. D. Dunitz, A. Gavezzotti, Chem. Soc. Rev. 2009, 38, 2622-2633.

[72] J. D. Dunitz, ChemBioChem 2004, 5, 614-621. 
[73] J. K. Cockcroft, A. Rosu-Finsen, A. N. Fitch, J. H. Williams, CrystEngComm 2018, 20, 6677-6682.

[74] K. E. Riley, G. Cui, K. M. Merz, J. Phys. Chem. B 2007, 111, 5700-5707.

[75] J. B. Doyon, E. A. M. Hansen, C.-Y. Kim, J. S. Chang, D. W. Christianson, R. D. Madder, J. G. Voet, T. A. Baird, C. A. Fierke, A. Jain, Org. Lett. 2000, 2, 2557-2558.

[76] C. Y. Kim, J. S. Chang, J. B. Doyon, T. T. Baird, C. A. Fierke, A. Jain, D. W. Christianson, J. Am. Chem. Soc. 2000, 122, 12125-12134.

[77] K. Raha, A. J. Van Der Vaart, K. E. Riley, M. B. Peters, L. M. Westerhoff, H. Kim, K. M. Merz, J. Am. Chem. Soc. 2005, 127, 6583-6594.

[78] A. Scozzafava, L. Menabuoni, F. Mincione, F. Briganti, G. Mincione, C. T. Supuran, J. Med. Chem. 2000, 43, 4542-4551.

[79] X. De Leval, M. Ilies, A. Casini, J. M. Dogné, A. Scozzafava, E. Masini, F. Mincione, M. Starnotti, C. T. Supuran, J. Med. Chem. 2004, 47, 2796-2804.

[80] F. Abbate, A. Casini, A. Scozzafava, C. T. Supuran, J. Enzyme Inhib. Med. Chem. 2003, 18, 303-308.

[81] A. Cecchi, J. Y. Winum, A. Innocenti, D. Vullo, J. L. Montero, A. Scozzafava, C. T. Supuran, Bioorganic Med. Chem. Lett. 2004, 14, 5775-5780.

[82] D. Vullo, A. Scozzafava, S. Pastorekova, J. Pastorek, C. T. Supuran, Bioorganic Med. Chem. Lett. 2004, 14, 2351-2356.

[83] F. Mincione, M. Starnotti, E. Masini, L. Bacciottini, C. Scrivanti, A. Casini, D. Vullo, A. Scozzafava, C. T. Supuran, Bioorganic Med. Chem. Lett. 2005, 15, 3821-3827.

[84] S. Pastorekova, D. Vullo, A. Casini, A. Scozzafava, J. Pastorek, I. Nishimori, C. T. Supuran, J. Enzyme Inhib. Med. Chem. 2005, 20, 211-217.

[85] F. Pacchiano, M. Aggarwal, B. S. Avvaru, A. H. Robbins, A. Scozzafava, R. McKenna, C. T. Supuran, Chem. Commun. 2010, 46, 8371-8373.

[86] M. Y. Mboge, B. P. Mahon, N. Lamas, L. Socorro, F. Carta, C. T. Supuran, S. C. Frost, R. McKenna, Eur. J. Med. Chem. 2017, 132, 184-191.

[87] F. Pacchiano, F. Carta, P. C. McDonald, Y. Lou, D. Vullo, A. Scozzafava, S. Dedhar, C. T. Supuran, J. Med. Chem. 2011, 54, 1896-1902.

[88] S. Pastorekova, R. J. Gillies, Cancer Metastasis Rev. 2019, 38, 65-77.

[89] P. C. McDonald, S. Chia, P. L. Bedard, Q. Chu, M. Lyle, L. Tang, M. Singh, Z. Zhang, C. T. Supuran, D. J. Renouf, S. Dedhar, Am. J. Clin. Oncol. 2020, 43, 484-490.

[90] W. Becker, K. C. Bhattiprolu, N. Gubensäk, K. Zangger, ChemPhysChem 2018, 19, 895-906.

[91] M. Pellecchia, D. S. Sem, K. Wüthrich, Nat. Rev. Drug Discov. 2002, 1, 211-219.

[92] C. Dalvit, A. Vulpetti, $\dagger$ Lavis, 2018, 62, 2218-2244.

[93] K. E. Arntson, W. C. K. Pomerantz, J. Med. Chem. 2016, 59, 5158-5171.

[94] J. Jiménez-Barbero, B. Linclau, A. Ardá, N. C. Reichardt, M. Sollogoub, L. Unione, S. P. Vincent, Chem. Soc. Rev. 2020, 49, 3863-3888.

[95] C. Dalvit, A. Vulpetti, ChemMedChem 2011, 6, 104-114.

[96] M. P. Gamcsik, J. T. Gerig, FEBS Lett. 1986, 196, 71-74.

[97] Y. Takaoka, Y. Sun, S. Tsukiji, I. Hamachi, Chem. Sci. 2011, 2, 511-520.

[98] Y. Takaoka, Y. Kioi, A. Morito, J. Otani, K. Arita, E. Ashihara, M. Ariyoshi, H. Tochio, M. 
Shirakawa, I. Hamachi, Chem. Commun. 2013, 49, 2801-2803.

[99] K. Zimmermann, D. Joss, T. Müntener, E. S. Nogueira, M. Schäfer, L. Knörr, F. W. Monnard, D. Häussinger, Chem. Sci. 2019, 10, 5064-5072.

[100] S. Thibaudeau, H. Carreyre, A. Mingot, in Mod. Synth. Process. React. Fluorinated Compd. Prog. Fluor. Sci., Elsevier Inc., 2017, pp. 349-388.

[101] A. Gimeno, P. Valverde, A. Ardá, J. Jiménez-Barbero, Curr. Opin. Struct. Biol. 2020, 62, 22-30.

[102] P. Valverde, J. I. Quintana, J. I. Santos, A. Ardá, J. Jiménez-Barbero, ACS Omega 2019, 4, 1361813630.

[103] J. D. Martínez, A. I. Manzano, E. Calviño, A. De Diego, B. Rodriguez De Francisco, C. Romanò, S. Oscarson, O. Millet, H. J. Gabius, J. Jiménez-Barbero, F. J. Cañada, J. Org. Chem. 2020, 85, 1607216081. 